REJ - Revista de Estudios de la Justicia - No 9 - Año 2007

\title{
PROHIBICION DE LA REFORMATIO IN PEIUS Y LA REALIZACION DE NUEVO JUICIO (IR POR LANA Y SALIR TRASQUILADO)
}

Ignacio Barrientos Pardo

I.- Introducción. II.- Concepto, fundamento y finalidad de la probibición de la reformatio in peius en la doctrina procesal. III.- Concepto, fundamento y finalidad de la probibición de la reformatio in peius en la jurisprudencia iberoamericana. IV.- La prohibición de la reformatio in peius como integrante del debido proceso. $V$.- La probibición de la reformatio in peius en el nuevo sistema procesal penal chileno. VI.Posiciones doctrinales en relación a la aplicación de la probibición de reformatio in peius al nuevo juicio o juicio de reenvio. VII.- Consideraciones que permiten optar por la tesis de la maximización de la eficacia del derecho al recurso. VIII.- Palabras finales.

\section{INTRODUCCION}

Probablemente el título de este trabajo ${ }^{1}$ denote la preocupación estratégica presente en el razonamiento de un defensor que habiendo obtenido una decisión judicial en cierto modo favorable, considerando la pretensión fiscal, decide o es requerido por su cliente para que deduzca un recurso de nulidad.

Probablemente ese defensor preferirá deducir un recurso fundado en algunas de las causales del art. 373 del CPP y pedir, además, la aplicación del art. 385 del CPP, esto es, la emisión de sentencia de reemplazo, que interponer un recurso basado en algún motivo del art. 374, pues en este último caso, de acogerse el recurso, se anulará la sentencia y el juicio y deberá realizarse un segundo juicio. Planteada esa posibilidad, la cuestión radica en que en este nuevo juicio la decisión podría ser más desfavorable que en el primero, por lo que la determinación de recurrir tendrá que superar no sólo el filtro de la concurrencia de un motivo legal, sino que el de la asunción del riesgo de "ir por lana y salir trasquilado".

De acuerdo a mi experiencia personal, ésta es una tesitura en la que usualmente se encuentran los abogados que ejercen la defensa. Me arriesgo a decir

\footnotetext{
* Licenciado en Ciencias Jurídicas de la Universidad de Valparaíso. Asesor Jurídico de la Defensoría Regional de Antofagasta. Candidato a Doctor, Universidad Autónoma de Madrid.

Mis agradecimientos a mis colegas de la Defensoría Regional de Antofagasta por el apoyo recibido. Especialmente agradezco a Pedro Casanueva, Loreto Flores y Mario Fuentealba y mi reconocimiento, por su colaboración, a Paola Garrido. No puedo omitir mi gratitud a Angélica Escobar y Pamela Ponce, por la lectura del primer borrador y sus valiosos comentarios.

${ }^{1} \mathrm{~J}$. Maier señala que esta expresión, referida a la aplicación de la prohibición de reformatio in peius, se encuentra en Ayán, Manuel, Recursos en materia penal, Ed. Lerner, Córdoba (Arg.), 1985, pp. 166167 , la que a su vez se atribuye a don Niceto Alcalá-Zamora y Castillo.
} 
Barrientos - Prohibición de reformatio in peius...

que se trata de un elemento que de alguna manera está en el ADN de todo defensor y cuyo efecto principal es la autolimitación en la actividad recursiva. ${ }^{2}$

Un caso real en que operó la reformatio in peius en el segundo juicio podrá aclarar la situación que suscita este análisis:

En la causa RIT No 19-2006, RUC 0500234830-8 del Sexto Tribunal de Juicio Oral en lo Penal de Santiago, con fecha 24 de marzo de 2006, se condenó a I.A.T.M. a la pena de 4 años de presidio menor en su grado máximo como autor de homicidio simple y a la pena de 60 días de prisión en su grado máximo por lesiones menos graves, sin beneficios de la Ley $\mathrm{N}^{\circ} 18.216$. La defensa recurrió de nulidad fundado en los motivos absolutos del art. 374 letra e y c del CPP. Se solicitó la nulidad de la sentencia y del juicio oral pues el tribunal no había motivado la no concesión de la libertad vigilada. La Corte de Apelaciones de San Miguel, acogiendo lo señalado por la defensa en cuanto a la falta de motivación respecto del beneficio, anuló la sentencia y el juicio oral por sentencia de fecha 5 de mayo de 2006, Rol Ingreso $N^{\circ} 338-2006$. No hubo actividad recursiva del Ministerio Público. En el segundo juicio llevado a cabo en el mismo tribunal, por jueces no inhabilitados, por sentencia definitiva de fecha 19 de junio de 2006 se condenó al acusado a la pena de 5 años y un día de presidio mayor en su grado mínimo por el delito de homicidio simple y a multa de una UTM, como autor del delito de lesiones leves, lo que hizo absolutamente improcedente la concesión de beneficios. ${ }^{3}$

Las interrogantes que surgen son: ¿Rige para el segundo juicio el límite punitivo de la prohibición de la reformatio in peius? ¿El nuevo tribunal está limitado en el conocimiento y juzgamiento o, por el contrario, es plenamente libre para examinar los hechos y aplicar el derecho? ¿Podrá el Ministerio Público pedir que se aplique una pena superior a la que se impuso en la sentencia del primer juicio, si no recurrió contra dicha sentencia? ¿Puede sostenerse que el Ministerio Público se ha conformado con o ha consentido en la pena impuesta en el primer juicio y, que por ello, en cuanto ejecutor de la acción penal pública, ha modificado su

\footnotetext{
${ }^{2}$ En el mes de febrero de 2007 se realizó, con la colaboración invaluable de C. Arias, Jefe de la Unidad de Corte, una breve encuesta a nivel nacional en que se consultó a todos los defensores, institucionales y licitados, dependientes de la Defensoría Penal Pública, para que indicasen los casos en que no habían deducido un recurso de nulidad en que correspondía pedir la nulidad del juicio por temor a que, de anularse el primer juicio, la sentencia del segundo fuese más severa o no concediese los beneficios dispuestos en la primera. Los resultados fueron los siguientes: De un total de 166 defensores que respondieron la encuesta, 125 contestaron que nunca han estado en esa situación y 41 contestaron afirmativamente, cifra ésta última que representa un $24 \%$ de los defensores encuestados. Como muchos defensores señalaron más de un caso, el total de casos en que no se han deducido recurso de nulidad por temor a que en el segundo juicio se imponga una pena más severa aumenta a 75 , lo que en términos porcentuales significa (transformado cada caso en un imputado) un $45 \%$ del total de imputados representados por los defensores encuestados.

${ }^{3}$ Esta información fue proporcionada por Cristián Arias (Jefe de Unidad de Corte, Defensoría Nacional) y por Alejandro Viada (Jefe de Unidad de Estudios, Defensoría Metropolitana Sur), a quienes agradezco por su gentileza y apoyo. Gratitud que se extiende a sus respectivos equipos de trabajo.
} 
pretensión punitiva? O dicho de otro modo, ¿ha operado respecto del Ministerio Público, en la medida que no recurrió contra la sentencia, la institución de la cosa juzgada, una de cuyas consecuencias esenciales es el principio de non bis in ídem? ${ }^{4}$

Para responder estas preguntas conviene, (1) explicar en qué consiste y qué persigue la prohibición de la reformatio in peius; (2) explicar cuál es la jerarquía normativa de la prohibición de reformatio in peius, es decir si se trata de una regla legal o constitucional; (3) ocuparse brevemente del sistema de recursos procesales establecidos en el Código Procesal Penal (en adelante CPP); y; (4) enunciar las principales razones que arguyen las dos posiciones doctrinales que existen en la materia. Por último (5), formularemos, en base a las cuestiones planteadas precedentemente, algunas consideraciones que nos permitan optar por una u otra de las posiciones doctrinales, según si la estimamos más ajustada a los fundamentos y finalidades de la institución comentada, a su naturaleza y jerarquía normativa y al sistema de recursos existente en nuestro país.

\section{CONCEPTO, FUNDAMENTO Y FINALIDAD DE LA PROHIBICION DE LA REFORMATIO IN PEIUS EN LA DOCTRINA PROCESAL}

En la doctrina procesal chilena no es fácil encontrar estudios sobre la prohibición de la reformatio in peius, especialmente en el ámbito procesal penal. ${ }^{5}$ Lo

\footnotetext{
4 No se puede dejar de mencionar que las leyes procesales penales de varios países latinoamericanos resuelven expresamente las dudas que se plantean. Así, se inclinan por la aplicación de la prohibición de la reforma peyorativa al segundo juicio o juicio de reenvío, los siguientes países: Perú (Art. 426, Código Procesal Penal Decreto Legislativo No 957, 29 de julio de 2004); Nicaragua (art. 400, Código Procesal Penal, 18 de diciembre de 2001); Costa Rica (art.451, Código Procesal Penal, Ley No 7594, 10 de diciembre de 1996); República Dominicana (art. 404, Ley N ${ }^{\circ}$ 72-02, 2 de julio de 2002); Bolivia (art. 413, Código Procesal Penal, 18 de mayo de 1999); Panamá (art.2463 sobre revisión, Código Judicial. Proceso Penal, 10 de marzo de 1987); Provincia de La Pampa (Arg.) (art. 413, Código Procesal Penal, entrada en vigencia en 2008); Brasil (art. 626 sobre revisión, Código de Proceso Penal, Ley No 3684, 1 de enero de 1942). Los códigos de otros países establecen el principio de nec reformatio in peius de tal forma que se puede aplicar al juicio de reenvío, v.gr.: Venezuela (art. 442, Código Orgánico Procesal Penal, 2 de octubre de 2001); Honduras (art. 350, Código Procesal Penal, Norma No 9-99-E, 30 de diciembre de 1999); Argentina (art. 445, Código Procesal Penal, Ley No 23.984, 9 de septiembre de 1991); El Salvador (art. 413, Código Procesal Penal, 20 de enero de 1997. En todo caso, el art. 440 sobre la solicitud de revisión aplica la no reforma peyorativa al nuevo juicio); Guatemala (art. 422, Código Procesal Penal, Decreto No 51-92, de 1992); Colombia (art. 215, Código de Procedimiento Penal, Ley No 600, 24 de julio de 2000). Fuente: www.cejamericas.org/

5 Ver, por ejemplo, Chahuán Sarrás, Sabas, Manual del Nuevo Procedimiento Penal, Editorial Jurídica Conosur Ltda., Santiago de Chile, 2001, p. 343; Cerda San Martín, Rodrigo, Etapa Intermedia. Juicio Oral y Recursos, Editorial Librotecnia, $1^{\circ}$ edición, Santiago de Chile, 2003, p. 272; Caroca, Alex, "Recursos en el nuevo sistema procesal penal", en VV.AA., Nuevo Proceso Penal, Editorial Jurídica Conosur Ltda., Santiago de Chile, 2000, pp. 297-331; Otero Lathrop, Miguel, Código Procesal Penal, LexisNexis Conosur, Santiago de Chile, 2002, pp-101-141; Tavolari Oliveros, Raúl, Instituciones del
} 
Barrientos - Prohibición de reformatio in peius...

anterior probablemente se explica por la inexistencia de esta institución en el antiguo Código de Procedimiento Penal. Las pocas y breves referencias a la prohibición de reforma en perjuicio no destacan su fundamento y finalidad, ni su condición de elemento integrante del contenido esencial del derecho al recurso y/o de defensa. Quizás quienes más se han extendido en el tratamiento de esta institución procesal han sido María Inés Horvitz Lennon y Julián López Masle, quienes señalan que esta garantía consiste en la prohibición que pesa sobre el tribunal que revisa una resolución jurisdiccional por la interposición de un recurso, de modificarla en perjuicio del imputado, cuando ella sólo hubiese sido recurrida por él o por otra persona autorizada por la ley, en su favor. Su finalidad inmediata consistiría, según estos autores, en impedir que el imputado sea perjudicado sorpresivamente por una resolución sin que haya podido defenderse de aquellos extremos de la misma que lo afectan. Admiten que si bien esta prohibición no está planteada legislativamente como expresión particular del derecho de defensa del imputado, en cuanto se admite también que beneficie a las partes acusadoras, no se debe olvidar que en cuanto garantía sólo puede jugar a favor del imputado. ${ }^{6}$

Ante la carencia de un tratamiento más profundo en la doctrina nacional, nuestra principal fuente serán procesalistas extranjeros, en cuyos países la institución analizada tiene aplicación desde hace muchos años.

El procesalista argentino Fernando De La Rúa, destaca el carácter de garantía constitucional de la prohibición de la reformatio in peius, sin perjuicio de ser, en su opinión, una manifestación de la limitación a los agravios (principio de congruencia). La jerarquía constitucional de la garantía comentada deriva de su íntima relación con el derecho de defensa. Así sostiene De La Rúa que el no agravamiento de la situación obtenida por el recurrente, que garantiza la prohibición, es consecuencia del objeto defensivo del recurso, ya que de lo contrario se privaría al recurso de su finalidad específica, esto es, de obtener una ventaja o un resultado más favorable del proceso. $^{7}$ A su vez, desde el punto de vista estrictamente procesal, la prohibición de la reformatio in peius es una consecuencia del principio de congruencia o correlación, según el cual la sentencia debe limitarse a las pretensiones que forman el objeto del proceso, que tiene en segunda instancia manifestaciones más específicas, más limitantes y rigurosas, ya que esta instancia tiene un objeto propio, que son las pretensiones impugnativas de los recurrentes, y la voluntad de éstos limita o condiciona más al juez del recurso. Por ello, sostiene De La Rúa, la competencia funcional del

Nuevo Proceso Penal. Cuestiones y Casos, Editorial Jurídica de Chile, Santiago de Chile, 2005. En los dos primeros libros indicados se trata escuetamente la prohibición de reformatio in peius, y en las tres obras restantes no existe ninguna referencia a ella.

${ }^{6}$ Horvitz Lennon, María Inés y López Masle, Julián, Derecho Procesal Penal Chileno, Tomo I, Editorial Jurídica de Chile, $1^{\circ}$ Reimpresión, Santiago de Chile, 2005, pp. 237-238.

7 De La Rúa, Fernando, "Límites de los recursos. La prohibición de reformatio in peius en materia penal y civil", en Teoría General del Proceso, Ediciones Depalma, Buenos Aires, 1991, p. 214. Esta sección fue publicada anteriormente publicada en la Revista La Ley, t. 1982, pp.102 y ss. 
tribunal de alzada está determinada por los motivos indicados por el recurrente en función de los agravios ocasionados por el fallo. ${ }^{8}$

En similar sentido, Jorge A. Clariá Olmedo, autor de varias obras de mucha difusión no sólo en Argentina, señala que la prohibición de la reformatio in peius, en cuanto regla de garantía que excluye la posibilidad de modificación de la sentencia dictada por el a quo en perjuicio del apelante o recurrente sin que haya mediado instancia impugnativa admitida de la parte contraria, es corolario de la limitación del objeto del recurso a los agravios expresados, y tiene como fundamento la evitación de restringir con riesgos la facultad de poner en acto una impugnación.

Para Lino Enrique Palacio, otro insigne profesor argentino, la prohibición de reforma en perjuicio del acusado tiene un inequívoco fundamento constitucional, pues preserva la vigencia de la garantía de la defensa en juicio y del derecho de propiedad en tanto, respectivamente, impide el empeoramiento de una situación jurídica frente a un recurso que la ley concede, precisamente, para asegurar su eventual mejora y asegura la estabilidad de las resoluciones judiciales que en los aspectos no impugnados configuran un derecho adquirido para la parte a quien benefician. ${ }^{10}$

El profesor y juez argentino Julio Maier destaca, entre otros, dos aspectos de la institución que analizamos. Nos recuerda, primero, que si bien la Corte Suprema argentina ha reiterado que la prohibición de la reformatio in peius es también una garantía constitucional, cuya inobservancia afecta al debido proceso y lesiona el derecho de defensa del acusado, el acento debe ser puesto en que la manifestación de voluntad concreta del impugnante acerca de los motivos por los que el fallo resulta injusto (los agravios) constituye la frontera de la competencia (de la potestad) del tribunal ${ }^{11}$; esto como consecuencia de la vigencia en materia penal del principio acusatorio. En segundo lugar, señala que el fundamento político de la institución y lo que confirma su razón de ser es la seguridad jurídica;

\footnotetext{
${ }^{8}$ Ibidem, p. 212. Los tribunales superiores argentinos han seguido esta tesis y han planteado que el resolver agravar la pena existiendo sólo impulso recursivo de la defensa implica obrar con falta de jurisdicción. Desde 1954 (caso Bianchi de Piccaluga, Rosa (Suc.) la Corte Suprema argentina ha señalado que no hay jurisdicción de alzada sin un recurso interpuesto y mantenido ante el tribunal de recurso. Esto ha sido ratificado en el Fallo "Olmos" de 9 de mayo de 2006, del que más adelante nos ocupamos.

9 Clariá Olmedo, Jorge. A., Derecho Procesal, Tomo II, Estructura del Proceso, Ediciones Depalma, Buenos Aires, 1983, p. 304.

10 Palacio, Lino Enrique, Los recursos en el proceso penal, Abeledo-Perrot, Buenos Aires, 1998, p. 34.

11 Maier, J., Derecho Procesal Penal, Tomo I, Fundamentos, Editores del Puerto, Buenos Aires, 2002, $2^{\mathrm{a}}$ edición, $2^{\text {a }}$ reimpresión, p. 590-592. Aunque no lo diga expresamente J. Maier se sitúa entre quienes ven a la interdicción de reformatio in peius como una manifestación del principio de congruencia y, en ese sentido, vinculada con el derecho de defensa.
} 
Barrientos - Prohibición de reformatio in peius...

de lo contrario recursos perfectamente fundados no se interpondrían aceptándose sentencias injustas- por temor a la agravación de las consecuencias. ${ }^{12}$

Finalmente, Claus Roxin, poniendo de relieve la finalidad contradisuasiva de la prohibición de la reformatio in peius, señala que ésta pretende lograr que nadie se abstenga de interponer un recurso por el temor de ser penado de un modo más severo en la instancia siguiente. ${ }^{13}$

\section{CONCEPTO, FUNDAMENTO $Y$ FINALIDAD DE LA PROHIBICION DE LA REFORMATIO IN PEIUS EN LA JURISPRUDENCIA IBEROAMERICANA}

La prohibición de la reformatio in peius, llamada también reforma peyorativa, tiene una faz doble. Por un lado, es un límite jurisdiccional-punitivo que se autoimpone el Estado, dirigido al tribunal y al Ministerio Público, y por otro, una garantía procesal que constituye un elemento esencial del derecho a un acceso efectivo a los recursos procesales.

La Sala Constitucional del Tribunal Supremo de Justicia de Venezuela, (caso: Henry Prada y otros No. 811/2005 del 11 de mayo de 2005) señaló que,

"La consagración legal de la prohibición de reformatio in peius nace en razón de la necesidad de preservar el principio acusatorio para alcanzar la mayor independencia y equilibrio del juez, sin que éste pueda anular o sustituir las funciones atribuidas a las partes en el proceso. Dicha prohibición se sostiene sobre tres puntales: la máxima 'tantum apellatum, quantum devolutum", el principio de impetración y el principio acusatorio. Los dos primeros son formulaciones diferentes de una misma situación: la disponibilidad de los derechos o el principio dispositivo; mientras que, el principio acusatorio comporta el requisito de contradicción en el proceso penal, referido a su vez a garantizar la posición acusadora, la defensora y la relación entre ambas". (Subrayado del autor)

La prohibición de la reformatio in peius constituye un límite en dos sentidos. Un límite jurisdiccional y un límite punitivo. Así el ejercicio de la actividad jurisdiccional del tribunal que conoce del recurso se ve limitada en cuanto el recurrente quedará a salvo de la posibilidad de que la función revisora exceda los términos en que formuló su recurso, es decir, los pronunciamientos de la sentencia impugnada que no fueron cuestionados quedan a firme, cuando no ha mediado impugnación de la contraria. Asimismo, y como efecto del anterior, la prohibición de la reforma peyorativa dirigida a los órganos del Estado que intervienen en la persecución penal, frente a la inactividad recursiva del Ministerio Público, implica que no se puede imponer una pena más gravosa que la emanada

\footnotetext{
12 Ibidem, p. 593.

${ }^{13}$ Roxin, Claus, Derecho Procesal Penal, Editores del Puerto, Buenos Aires, 2000, p. 454-455.
} 
del proceso en que se dictó la sentencia recurrida por el acusado. ${ }^{14}$ En este sentido, la interdicción de la reformatio in peius impone al tribunal que conoce del recurso una doble abstención: no pronunciarse sobre aspectos no cuestionados por el recurrente ${ }^{15} \mathrm{y}$ no agravar la pena.

Lo anterior se corrobora por la jurisprudencia reiterada del Tribunal Constitucional español que ha declarado que,

"La reformatio in peius, o reforma peyorativa, constituye una modalidad de incongruencia procesal que tiene lugar cuando el recurrente, en virtud de su propio recurso, ve empeorada o agravada la situación creada o declarada en la resolución impugnada, de modo que lo obtenido con la resolución que decide el recurso tiene un efecto contrario al perseguido por el recurrente, que era, precisamente, eliminar o aminorar el gravamen sufrido con la resolución objeto de impugnación”. ${ }^{16}$

Por su parte, la Corte Constitucional de Colombia sostiene que la prohibición de la "reformatio in peius",

“... es un principio general del derecho procesal y una garantía constitucional que hace parte del derecho fundamental al debido proceso (CP art. 29). Ella es consecuencia de la regla insita en la máxima latina "tantum devolutum quantum appelatum", en virtud de la cual se ejerce la competencia del juez superior. El ejercicio de las competencias judiciales radicadas en el juez superior y su límite, ambos, se suscitan y a la vez se limitan por virtud de la impugnación y las pretensiones que ella involucra”. (Sentencia T-474/1992, subrayado mío)

"El principio non reformatio in pejus puede catalogarse como "una manifestación del principio de congruencia, según el cual las pretensiones del recurrente y su

\footnotetext{
14 Según Ayán, Manuel: "El imputado tiene derecho a que la nueva sentencia, no mediando recurso acusatorio, no sea para él más gravosa que la sentencia anulada”, Recursos en materia penal, Ed. Lerner, Córdoba, (Arg.), 1985, p. 171. Del mismo autor ver "La prohibición de la reformatio in peius", en Cuadernos de los Institutos, Ed. Universidad Nacional de Córdoba (Arg.), 1969, № 105, pp. $161 \mathrm{y} \mathrm{ss}$

${ }^{15}$ Esto es, en nuestro ordenamiento jurídico, una consecuencia del art. 360 inciso $1^{\circ}$ del CPP. Se trata de un caso de prohibición de ultra petita. Por ello es que se dice que la prohibición de la reformatio in peius, contemplada en el art. 360 inciso $3^{\circ}$, es una consecuencia del principio de congruencia procesal según el cual las pretensiones del recurrente y su voluntad de interponer el recurso, condicionan la competencia del juez que conoce del mismo. Así lo ha declarado, por ejemplo, la Corte Constitucional de Colombia en sentencia T-741 del 22 de junio del 2000. Conviene también recordar que el procesalista uruguayo Enrique Vescovi expresa, partiendo de la base que la expresión de agravios es la acción de la segunda instancia como forma de manifestación del principio de la congruencia, que resultaría inconsecuente admitir que el tribunal de alzada pueda ir más allá de lo pedido por el apelante. Agrega, E. Véscovi, que lo antes dicho es consecuencia del principio dispositivo del "ne procedat iure ex officio" y "nemo index sine actore". Vescovi, Enrique, Los Recursos Judiciales y demás Medios Impugnativos en Iberoamérica, Ediciones Depalma, Buenos Aires, 1988, p.163.

16 Ver: STCE 23/2003; STCE 196/2000; STCE 120/1995.
} 
Barrientos - Prohibición de reformatio in peius...

voluntad de interponer el recurso, condicionan la competencia del juez que conoce del mismo. Lo que el procesado estime lesivo de sus derechos, constituye el ámbito exclusivo sobre el cual debe resolver el ad quem: "tantum devolutum quantum appellatum". (Sentencia C-583/1997)

El fundamento de este instituto procesal, tributario del principio acusatorio $^{17}$, es garantizar al acusado la mayor libertad y tranquilidad para recurrir, que se obtiene cuando aquel tiene la certeza que nunca su propia actividad recursiva podrá perjudicarlo más que la propia sentencia impugnada. De lo contrario un acusado contra el que se ha dictado fallo condenatorio puede resultar compelido a sufrir la sentencia injusta, en su criterio, antes que correr el riesgo de que ésta se modifique en su perjuicio.

En el ámbito del ejercicio de los medios de impugnación, la prohibición de la reformatio in peius es una garantía procesal, cuya finalidad es evitar que el acusado contra el que se ha dictado sentencia condenatoria se vea disuadido, por temor a empeorar su situación procesal, de ejercer su derecho constitucional a los recursos legalmente establecidos en la Ley. ${ }^{18}$

Para determinar si la prohibición de reforma peyorativa se aplica al nuevo juicio o juicio de reenvío es necesario establecer si el efecto contradisuasivo de la prohibición de la reformatio in peius tiene sentido tanto si lo que se pretende es la revisión del fallo condenatorio a través de una apelación, cuanto si lo que procura es anular sólo la sentencia y no el juicio, o anular ambos y pedir la realización de un nuevo juicio.

La respuesta a algunas de las preguntas que han ido surgiendo en estas primeras páginas debe partir de la comprensión de la lógica recursiva de la defensa. Conviene tener en cuenta que cuando el recurso se interpone por la defensa el objetivo no es otro que obtener la modificación de la sentencia en su favor, sin correr ningún riesgo. Si existiese algún riesgo, por nimio que sea, cualquier condenado se plantearía si acaso no es mejor conformarse con lo obtenido (como en los concursos de televisión) y renunciar a impugnar la sentencia.

\section{LA PROHIBICION DE LA REFORMATIO IN PEIUS COMO INTEGRANTE DEL DEBIDO PROCESO}

Salvo el caso de Colombia ${ }^{19}$, la mayoría de los países no contemplan en sus textos constitucionales la prohibición de la reformatio in peius como garantía.

\footnotetext{
${ }_{17}$ Sobre el principio acusatorio, ver: STCE 194/2005; STCE 230/1997.

18 Ver: STCE 143/1988; STCE 120/1995; STCE 23/2003. También Fallo “Olmos", Corte Suprema de la Nación Argentina, de 9 de mayo de 2006.

${ }^{19}$ La Constitución Política de Colombia de 1991 en su Capítulo 1, Título II, artículo 31 dispone:

"El superior no podrá agravar la pena impuesta cuando el condenado sea apelante único."
} 
REJ - Revista de Estudios de la Justicia - No 9 - Año 2007

No obstante, existe consenso que esta institución tiene rango constitucional, como integrante del debido proceso y, concretamente, del derecho de defensa.

Así lo han sostenido los tribunales superiores de justicia y los tribunales constitucionales de la casi totalidad de los países del ámbito hispanoamericano.

El Tribunal Constitucional de Perú ha señalado que la interdicción de la reforma peyorativa de la pena,

"... es una garantía del debido proceso implícita en nuestro texto constitucional. Si bien tal interdicción se identifica íntimamente con el derecho de defensa, pues agravar una pena para condenar por un ilícito que no haya sido materia de acusación, importa una grave afectación del mentado derecho, es indudable que la proscripción de la reformatio in peius también tiene una estrecha relación con el derecho de interponer recursos impugnatorios". (Sentencia del expediente 19182002-HC/TC, publicada el 31 de octubre del 2003) ${ }^{20}$

La Sala de Casación Penal del Tribunal Supremo de Justicia de Venezuela sostuvo en un fallo del 2006 que,

"Esta Sala considera, tomando en cuenta las observaciones antes señaladas, que la recurrida violó el artículo 434 del Código Orgánico Procesal Penal por falta de aplicación; y en cumplimiento del deber que tiene el Estado de garantizar a todo imputado el respeto al debido proceso, dentro del cual se incluye la prohibición de la reforma de la sentencia en perjuicio del procesado.

La presente decisión no puede vulnerar el principio de la probibición de la reforma en perjuicio, previsto en el artículo 442 del Código Orgánico Procesal Penal, con el cual el legislador ha procurado la mayor garantía al derecho a la defensa, evitando que el pretendido beneficio a que se aspira a través del recurso interpuesto se convierta en un perjuicio para el acusado al desmejorar su situación jurídica”. (Sentencia N 235 del 30/05/2006)21

\footnotetext{
${ }^{20}$ En el mismo sentido, el Tribunal Constitucional peruano en Exp. No. 0806-2006-PA/TC, Palmer Pastor Velásquez, de 13 de marzo de 2006, ha expresado que: "Uno de esos derechos implícitos a la tutela procesal efectiva es la prohibición de la reformatio in peius. En efecto, en reiterada jurisprudencia este tribunal ha señalado que "[] a interdicción de la reformatio in peius o "reforma peyorativa de la pena", es una garantía del debido proceso implícita en nuestro texto constitucional, la cual se relaciona con los derechos de defensa y de interponer recursos impugnatorios. De acuerdo con dicha garantía, el órgano jurisdiccional que conoce de un proceso en segunda instancia no puede empeorar la situación del recurrente en caso de que sólo éste hubiese recurrido la resolución emitida en primera instancia."

${ }^{21}$ La misma Sala ha sostenido en sentencia No 840 del 14/06/2000 que: "La prohibición de la reformatio in peius es una garantía fundamental que forma parte del derecho al debido proceso y tiene por finalidad evitar que el imputado sea sorprendido ex officio con una sanción que no ha tenido oportunidad de rechazar. Por lo que su naturaleza es, además, de limitar al poder punitivo del Estado, es la de garantizar la efectividad del derecho fundamental de defensa y de favorecer al condenado con la revisión de la sentencia respecto a las pretensiones solicitadas, garantizando así la operatividad del sistema acusatorio". Congruente con el pronunciamiento del Tribunal Supremo Venezolano el Juzgado Superior Décimo en lo Civil, Mercantil y del Tránsito de la
} 
Barrientos - Prohibición de reformatio in peius...

La Corte Suprema de Justicia de la Nación Argentina, en la sentencia dictada en la causa "Olmos, José Horacio; De Guernica, Guillermo Augusto s/ estafa" de 9 de mayo de 2006 estableció que,

“... la sentencia de reenvío conculcó la garantía constitucional en juego ${ }^{22}$ toda vez que agravó la situación del procesado originada en el fallo anterior de la alzada que había sido anulado a instancia suya. En síntesis, cabe concluir que resultaría ilógico concederle al imputado la facultad de impugnación, y, al mismo tiempo, exponerlo al riesgo de que por el ejercicio de esta potestad -en ausencia de recurso de la parte acusadora- su situación procesal se vea empeorada, puesto que de esta manera se lo colocaría en la disyuntiva de correr ese riesgo o consentir una sentencia que considera injusta" (Voto de la mayoría) ${ }^{23}$.

Sin perjuicio del reconocimiento constitucional de la prohibición de la reformatio in peius contenido en la carta magna colombiana, en sentencia T-741 del 22 de junio del 2000, Exp. T-308.369, la Corte Constitucional, citando la sentencia T-474 de 1992, ha razonado sobre aquella garantía manifestando que,

"La interdicción de la reforma en perjuicio del condenado constituye, igualmente, una garantía procesal fundamental del régimen de los recursos, a su vez contenido en el derecho de defensa y en el núcleo esencial del derecho al debido proceso".

"También se analizó cómo la prohibición de la agravación en lo peor es desarrollo del principio del debido proceso. Se dijo: "Se trata de un juego limpio -que, en el fondo, tal es el debido proceso- que ninguna de las partes puede infringir y mucho menos el Estado a cuyo cargo está la guarda de la garantía. Hay oportunidades y mecanismos adecuados para enmendar errores. Su enmienda, así se juzgue de alta conveniencia, no puede tener lugar en cualquier

Circunscripción Judicial del Área Metropolitana de Caracas, con fecha 16 de agosto de 2006, Expediente $\mathrm{N}^{\circ} 5.364$ dictaminó que: "La reformatio in peius (reforma del fallo en perjuicio del apelante), consiste en la prohibición que tiene el juez superior de empeorar la situación del apelante, en los casos en que no ha mediado recurso de su contraparte. Consiste en la prohibición de que el órgano ad quem exceda sustancialmente los límites en que está formulado el recurso, acordando una agravación de la sentencia, con la reforma de la misma, en beneficio de quien no apeló y en perjuicio del único que lo hizo, se concede una ventaja indebida a una de las partes y se rompe con el equilibrio procesal. La reformatio in peius está muy ligada al problema de la congruencia, que es una derivación del debido proceso y de la tutela judicial efectiva... “"

${ }^{22} \mathrm{El}$ voto de mayoría se refiere al derecho de defensa.

${ }^{23}$ La Cámara Nacional de Casación Penal (Arg.) se ha pronunciado acerca de este concepto, en el sentido de que: "La prohibición de la reformatio in peius se sostiene sobre la base de dos recaudos, esto es, la falta de recurso acusatorio y la agravación de la pena. Por ello, incurre en inobservancia del referido principio y consecuente violación de las garantías de defensa en juicio y propiedad, la sentencia que coloca al imputado como único apelante en una situación más desfavorable que la que resultaba del pronunciamiento recurrido". (Sala III, "Barrita José s/ Recurso de Casación". Rta. 11/06/99.). Asimismo, Ver: C.A. Contrav. y de Faltas C.A.B.A. Causa 15850-00/CC/06 Miranda Vera, Ramón s/ inf. art. 83 ley 1472-Apelación- Sala III, Agosto 14 de 2006, Sentencia No 392- 06. 
momento y bajo cualquier condición que la norma superior no haya previsto. Porque lo que se juzga un interés general no puede sacarse avante por encima de la propia normatividad que lo consagra y delimita. Proceder de ese modo, sería subrogar la voluntad del funcionario a la Constitución y, por ende, destruir el Estado de Derecho en beneficio de intereses de ocasión, así se juzguen de la más alta estirpe."

Por su parte, el Tribunal Constitucional Español en STC 16/2000, de 16 de enero, expresó que si bien,

“... el artículo 24.1 CE no constitucionaliza la regla que prohíbe la reformatio in peius, aun cuando, no obstante, represente un principio procesal que forma parte del derecho a la tutela judicial efectiva a través del régimen de garantías legales de los recursos y, en todo caso, de la prohibición constitucional de la indefensión. Al proscribir la indefensión excluye, por tanto, toda posibilidad de reforma de la situación jurídica definida en la primera instancia que no sea consecuencia de una pretensión frente a la cual, aquél en cuyo daño se produce tal reforma, no haya tenido ocasión de defenderse..."

"Es esa conexión necesaria entre la prohibición de la reformatio in peius y la interdicción constitucional de la indefensión la que presta trascendencia constitucional a las infracciones de tal regla..." 24

Con la cita de fallos de tribunales de países del ámbito hispanoamericano lo único que hemos pretendido es dejar establecido con absoluta claridad que existe consenso que la prohibición de la reforma peyorativa integra el código genético del derecho al recurso y del derecho de defensa. Desprovisto de aquélla, estos derechos pierden fuerza y eficacia, quedando sujeto más a decisiones de carácter estratégico o de conveniencia procesal, que a consideraciones o evaluaciones acerca de la justicia o corrección de una resolución.

\section{LA PROHIBICION DE LA REFORMATIO IN PEIUS EN EL NUEVO SISTEMA PROCESAL PENAL CHILENO}

La principal característica del nuevo régimen de recursos establecido en el CPP es la eliminación del recurso de apelación en el juicio oral. Esta eliminación está determinada por la exigencia, propia de un procedimiento oral, controversial y público, que el fundamento fáctico de la sentencia provenga de la apreciación directa de las pruebas que los jueces orales obtienen en el juicio. La revisión de la sentencia por parte de jueces que no han participado en el juicio oral y que toman conocimiento de él con posterioridad, le privaría centralidad a aquél. Para evitar

\footnotetext{
${ }^{24}$ En sentencia No 238/2000, de 16 de octubre, el TCE falló que: “2. Aplicando los criterios expuestos al presente caso, resulta obligado estimar la pretensión de amparo deducida por la actora, ya que es patente que la sentencia impugnada ha incurrido en una reforma peyorativa de la posición jurídica de la apelante en términos incompatibles con el derecho fundamental a la tutela judicial efectiva sin indefensión".
} 
Barrientos - Prohibición de reformatio in peius...

ese pernicioso resultado, es decir, para mantener la centralidad del juicio oral, el recurso de apelación debió ser vedado en relación a las resoluciones del tribunal de juicio oral, incluida la sentencia definitiva.

No obstante lo anterior, el mencionado recurso de apelación se mantuvo vigente en relación con otras resoluciones (sobreseimientos, resolución que ordena alguna restricción de derechos a los intervinientes), entendiéndose necesario el control de dichas decisiones por un tribunal superior. También se mantuvo el recurso de apelación en el procedimiento abreviado, en el que no concurren las razones antes expuestas, especialmente la necesidad de privilegiar la inmediación, ya que en este caso, por la naturaleza del procedimiento, el juez falla en base a los antecedentes de la investigación.

El legislador para cumplir el mandato constitucional del debido proceso y los tratados internacionales incorporados al ordenamiento nacional creó el recurso de nulidad respecto de los juicios orales, simplificados u ordinarios. Este recurso es procedente, tanto si se trata de errores in procedendo o de errores in iudicando. ${ }^{25} \mathrm{La}$ regla general, en cuanto a los efectos que produce la resolución que acoge el recurso, es que ésta determina la nulidad de la sentencia y del juicio oral, salvo el caso excepcional del art.385 del CPP, único en que procede la dictación de sentencia de reemplazo.

Conviene recordar que el sistema procesal penal anterior establecía expresamente, en los arts. 528 y 548 del Código de Procedimiento Penal, la posibilidad de la reformatio in peius, al señalar el primer precepto que "aún cuando la apelación haya sido deducida por el procesado podrá el tribunal de alzada modificar la sentencia en forma desfavorable al apelante".

A su vez, el art. 548, del mismo texto señalaba que "en los casos en que la Corte Suprema acoja el recurso deducido en interés del condenado, podrá aplicar a éste, como consecuencia de la causal acogida y dentro de los límites que la ley autoriza, una pena más severa que la impuesta por la sentencia invalidada".

En la actualidad, la prohibición de la reformatio in peius está consagrada dentro de las disposiciones generales que regulan los recursos en el CPP, específicamente, en el inciso final del artículo 360, que dispone que "si la

\footnotetext{
25 Una sentencia puede contener errores de juicio o de actividad, lo que la doctrina procesal denomina errores in iudicando y errores in procedendo (vicio de actividad o defecto de construcción). Los primeros, son errores de derecho que se producen por falta de aplicación o aplicación indebida de una norma sustancial o por interpretación errónea. Los segundos, en cambio, nacen de la inejecución de la ley procesal, en cuanto alguno de los sujetos del proceso no ejecuta lo que esta ley le impone (inejecución in omittendo), o ejecuta lo que esta ley prohíbe (inejecución in faciendo), o se comporta de un modo diverso del que la ley prescribe. Ver a este respecto sentencia $\mathrm{N}^{\circ} \mathrm{C}-252$ de 28 de febrero de 2001 de la Corte Constitucional de Colombia.
} 
resolución judicial hubiere sido objeto de recurso por un solo interviniente, la Corte no podrá reformarla en perjuicio del recurrente". ${ }^{26}$

Con esta norma nuestro país se puso al día con los estándares internacionales en materia de derechos humanos y con los modelos existentes en el Derecho Comparado y, además, con la propia legislación procesal civil, dado que la reforma en perjuicio es una institución proscrita en el Código de Procedimiento Civil. Se trataba de una diferencia que carecía de fundamento y justificación racional.

Si aplicamos al art. 360 del CPP el elemento gramatical de interpretación podríamos concluir que la prohibición de la reformatio in peius, por los términos empleados por el legislador, se aplica solamente cuando estamos frente a una sentencia de reemplazo, vía apelación o nulidad con aplicación del art. 385. Cuando el recurso de nulidad acogido deviene en la realización de un nuevo juicio dicha norma no es aplicable, por el uso categórico de la expresión Corte y por lo dispuesto en el artículo 386 del CPP.

La interrogante que quiero dejar lanzada antes de pasar a la siguiente sección, donde se exponen las distintas posiciones que se dan en esta materia, es si basta con la aplicación del mencionado criterio hermenéutico. O si, por el contrario, es necesaria una interpretación que procure el cumplimiento de la finalidad de la institución-garantía que se analiza, especialmente si se trata no sólo de interpretar una norma legal, sino un elemento que integra el contenido esencial de un derecho constitucional. Es conveniente recordar que la interpretación constitucional se rige no por los clásicos, y en ocasiones, estrechos criterios de interpretación del Código Civil.

\section{POSICIONES DOCTRINALES EN RELACION A LA APLICACION DE LA PROHIBICION DE LA REFORMATIO IN PEIUS AL NUEVO JUICIO O JUICIO DE REENVIO}

El profesor Julio Maier partiendo de la premisa que el derecho al recurso del condenado, significa, básicamente "el derecho a lograr un nuevo juicio", afirma que,

“c) El recurso y, eventualmente, el nuevo juicio constituyen un derecho del condenado [...] que no puede conducir a consecuencias jurídicas más graves para el condenado que el primer juicio, y cuyo límite máximo es la confirmación de la

\footnotetext{
${ }^{26}$ Esta norma pareciera descartar, en principio, la posibilidad de reforma in melius a favor del imputado cuando el único recurrente sea el Ministerio Público o el querellante particular. Para una fundada opinión en sentido contrario, ver: Horvitz Lennon, María Inés y López Masle, Julián, ob. citada, p.238.
} 
Barrientos - Prohibición de reformatio in peius...

sentencia (prohibición de la reformatio in peius) único "riesgo" que corre el condenado (ne bis in idem: persecución penal única). ${ }^{27}$

J. Maier, y antes otros autores ${ }^{28}$, sienta las bases de esta discusión que presenta dos posturas inconciliables y que se mantiene hasta el día de hoy. Una muestra de ello es el fallo en el caso "Olmos, José Horacio; De Guernica, Guillermo Augusto s/ estafa" de la Corte Suprema argentina de 9 de mayo de 2006.

A continuación expondré brevemente ambas tesis. A la tesis que sostiene que no es aplicable la prohibición de reformatio al juicio de reenvío la llamaré "la tesis del riesgo previsible libremente asumido". Por el contrario, la tesis que expresa su acuerdo con la aplicación de la prohibición de reformatio in peius la llamaré "la tesis de la maximización de la eficacia del derecho al recurso".

\section{Tesis del riesgo previsible libremente asumido.}

Esta tesis se apoya en las siguientes razones para afirmar su negativa a la aplicación de la prohibición de la reforma peyorativa en el juicio de reenvío:

a) Resultado o riesgo previsible asumido libremente. Este argumento se resuelve en sostener que el acusado al recurrir acepta libremente el riesgo que en el nuevo juicio se le imponga una pena más severa. Por ello se sostiene que la posibilidad de que el nuevo fallo acarree a los intereses del recurrente un gravamen mayor que el derivado de la resolución invalidada, constituye un resultado o un riesgo que el acusado, antes de deducir su recurso, pudo prever y asumir libremente. ${ }^{29}$

En su voto de disidencia en el caso "Olmos", los jueces doña Carmen Argibay y don Carlos Pereyra Gónzalez, de la Corte Suprema argentina, para fundar este argumento, añaden que aún cuando el derecho de defensa debe ser a

${ }^{27}$ Maier, J. Derecho Procesal Penal, Tomo I, Fundamentos, ob. citada, p.721. Similar afirmación hace J. Maier en "La impugnación del acusador: ¿un caso de ne bis in idem?", en que señala que: "Por último, el acusador no estará facultado a intentar recursos contra la sentencia absolutoria o de condena, circunstancia que permitirá reducir los casos que arriban a los tribunales de casación racionalmente -sin utilizar el recurso odioso (jurídicamente apreciado) de la limitación de la impugnación de condenas por parte del imputado- y que logrará que la condena originaria sea, además, el límite máximo de la consecuencia jurídica que se pudiera establecer en un nuevo juicio y una nueva condena (prohibición de la reformatio in peius), provocados sólo por recurso del $\begin{array}{lllllll}\text { condenado } \mathrm{o} & \mathrm{de} & \mathrm{su} & \text { defensor. (Subrayado mío). Ver http:// }\end{array}$ www.cienciaspenales.org/revista $\% 2012 /$ maier12.htm.

${ }^{28}$ Ver Clariá Olmedo, Jorge A., Tratado de Derecho Procesal Penal, Ediar, Buenos. Aires, $1969 \mathrm{~T}^{\circ}$. V. p. 467. También consultar a De La Rúa, F., "Límites de los recursos y prohibición de reformatio in peius en materia penal y civil", ob. citada.

${ }^{29}$ Fallo "Luppo" de la Corte Suprema de Justicia argentina, extraído de Carrió, Alejandro D., Garantías Constitucionales en el Proceso Penal, Hammurabi, $4^{\circ}$ edición actualizada y ampliada, $2^{\circ}$ reimpresión, Buenos Aires, 2003. p. 139. 
todas luces preservado, en el enjuiciamiento penal suelen existir situaciones en las que el imputado se halla ante diversas disyuntivas procesales que, dependiendo de la decisión tomada, pueden conducirlo a un cierto riesgo mediato o inmediato.

Los jueces Argibay y Pereyra dan ejemplos de casos en que el imputado asume, frente a una disyuntiva, determinados riesgos procesales. Señalan que conforme al ordenamiento ritual federal argentino, el imputado puede negarse a prestar declaración indagatoria. Pero si decide declarar deberá, en cierto modo, soportar el riesgo de que el juez de instrucción, al evacuar sus citas (cfr. art. 304 del Código Procesal Penal de la Nación), obtenga prueba de cargo. Lo mismo podría ocurrir ante un pedido de producción de pruebas por parte del propio imputado o su defensa que, introducidas en el debate, terminen jugando en su contra en virtud de la evaluación que de ellas pueda realizar el tribunal sentenciante. También el imputado suele hallarse en la disyuntiva de presentarse o no ante el juez que requiere su comparecencia y, en caso de aceptar dicho requerimiento, estará latente la posibilidad, por ejemplo, de ser sometido a prisión preventiva. ${ }^{30}$

Finalmente, afirman que una similar circunstancia de disyuntiva y riesgo ocurre cuando la propia defensa propugna la anulación del primer juicio y la realización de uno nuevo, denotando justamente una decisión de arriesgarse en una nueva chance antes de conformarse con la condena. Nada arbitrario ni sorpresivo para la defensa puede surgir del hecho de que -tras la pertinente acusación fiscal- pudieran recaer penas de mayor gravedad para los enjuiciados. ${ }^{31}$

b) Inexistencia de la sentencia del primer juicio. Con esto, se apunta a la idea que la nulidad implica que la sentencia y sus efectos desaparecen. Así se sostiene que la nulidad implica la inexistencia de la sentencia anulada y que no existen fundamentos para asignar ultraactividad a la individualización de las penas fijadas en la sentencia anulada. ${ }^{32}$

La sentencia del primer juicio no puede tener la virtualidad de limitar el juicio de reenvío porque al haber sido anulada perdió todos sus efectos. Este argumento está íntimamente ligado al que sostiene que por la naturaleza del juicio oral se produce una devolución completa de la jurisdicción al tribunal de reenvío. ${ }^{33}$

El Procurador General de la Corte Suprema argentino en el Caso "Olmos" sostuvo que la nulidad decidida comprendía tanto la sentencia

\footnotetext{
${ }^{30}$ Voto de disidencia de los jueces doña Carmen Argibay y don Carlos Pereyra Gónzalez, Fallo "Olmos", p. 18. Como se puede apreciar el argumento es absolutamente compatible con lo establecido en nuestro ordenamiento procesal penal.

31 Ibidem.

32 El informe del Procurador General de la Corte Suprema don Nicolás Eduardo Becerra en el Caso "Olmos", citando un anterior informe de la Procuraduría, señala que no es admisible reconocer a la sentencia aniquilada algún efecto remanente, Sección IV.

33 Ibidem.
} 
impugnada como el debate que le antecedía, pues se retrotrajo el trámite a la etapa inmediatamente anterior a la audiencia oral. ${ }^{34}$

c) No afectación del derecho de defensa. El curso de este argumento proviene de la idea que la defensa al recurrir, asume libremente el riesgo de ver empeorada su situación si se anula el juicio y se realiza uno nuevo. Nuevo juicio en que no se puede objetar que se haya afectado el derecho de defensa, pues en ningún caso el acusado se va a ver sorprendido por la sentencia finalmente dictada. ${ }^{35} \mathrm{El}$ mensaje que se desprende de esta línea argumental es que el acusado tiene plena conciencia de lo que enfrentará en el nuevo juicio y lo acepta.

d) Devolución plena de la jurisdicción al tribunal de reenvío. El razonamiento de quienes sostienen esta argumentación es que la naturaleza del juicio oral, en que tiene especial relevancia el principio de inmediación, impone la devolución completa de la jurisdicción al tribunal de reenvío. Así se sostiene que la declaración de nulidad de una sentencia a petición de la defensa, importa devolver al tribunal de reenvío, como consecuencia de la iniciativa del propio acusado, la jurisdicción que le fue deferida por el recurso interpuesto contra el fallo del tribunal de mérito.

$\mathrm{Al}$ anularse el primer fallo se revierten los poderes del tribunal " $a$ quo", conclusión que no se modifica por la circunstancia de que la ulterior actividad jurisdiccional se originara por un impulso procesal desarrollado exclusivamente por la defensa. ${ }^{36}$

Asimismo, se afirma que el nuevo debate entre partes plenamente habilitadas no es alcanzado por las limitaciones propias del recurso en cuyo marco se había resuelto su realización.

Claramente aquí la idea que predomina es que el juicio de reenvío es un juicio totalmente nuevo, en que las partes se enfrentan nuevamente a una instancia contradictoria o controversial en la que ambas partes debaten sobre posiciones adversas, pretensiones que no reconocen ninguna cortapisa en el derecho vigente. ${ }^{37}$

\footnotetext{
34 Ibidem.

${ }^{35}$ Estas ideas se encuentran en el voto de disidencia de los jueces de la Corte Suprema argentina en "Olmos", doña Carmen Argibay y don Carlos Pereyra.

${ }^{36}$ Fallo "Luppo" de la Corte Suprema de Justicia argentina, extraído de Carrió, Alejandro D., ob. citada, p. 139, en que señala que al anularse el primer fallo se han revertido los poderes al tribunal "a quo" y que "esta conclusión, por lo demás no se modifica por la circunstancia de que la ulterior actividad jurisdiccional se originara por un impulso procesal desarrollado exclusivamente por la defensa, habida cuenta de que la posibilidad que el proceso culmine con una condena aún mayor es un riesgo previsible que debe asumir quien utiliza un poder discrecional".

${ }^{37}$ Voto de disidencia de los jueces doña Carmen Argibay y don Carlos Pereyra, Fallo "Olmos", p. 16.
} 
Por último, se asevera que dada la inexistencia de la sentencia anulada, producida la restauración plena de las facultades del tribunal de reenvío se produce también la renovación de la facultad persecutoria del Estado, como si no hubiese ocurrido nada.

e) Procedencia exclusiva de la prohibición respecto de la jurisdicción apelada. Esta razón parte de la distinción entre instancia contradictoria e instancia revisora. En la primera, que es el caso del juicio de reenvío, el debate se realiza nuevamente y la jurisdicción del tribunal es restaurada completamente. En cambio, de no existir recurso fiscal, en el ámbito de la instancia revisora, el tribunal de alzada tiene por único objeto examinar los agravios de la defensa, por lo que una decisión a favor de la acusación excedería el interés del recurrente y, por ende, la competencia del tribunal.

Se sostiene que en el nuevo juicio, el tribunal que debe llevarlo a cabo cuenta con plena jurisdicción para resolver, pues no se trata de un supuesto de jurisdicción apelada, en el que el tribunal ad quem no tiene más poderes que los que caben dentro de los límites de los recursos deducidos. ${ }^{38}$

En fin, se declara que al realizarse el nuevo juicio y dictar sentencia aplicando penas más severas que las impuestas en el primer juicio, el tribunal de reenvío no actúa como tribunal de alzada o superior con competencia devuelta, sino como tribunal con plena jurisdicción. ${ }^{39}$

\section{Tesis de la maximización de la eficacia del derecho al recurso.}

Las razones de quienes sostienen esta tesis son las siguientes:

a) Mayor eficacia del derecho al recurso. Con este argumento, se expresa fuertemente la idea que la no aplicación de la prohibición de la reformatio in peius transformaría en ilusorio e ineficaz el derecho al recurso y, por añadidura, el derecho de defensa. La lógica de este argumento pretende evidenciar que el afectado por una sentencia que estima injusta puede decidir no recurrir para no arriesgarse a perder lo ya ganado en el juicio.

Así se dice que resultaría arbitrario o ilógico concederle al acusado la facultad de impugnación y, al mismo tiempo, exponerlo al riesgo de que por el ejercicio de dicha facultad, y sin existir recurso de la parte acusadora, su situación procesal se vea empeorada, colocándolo en la disyuntiva de correr el riesgo o consentir una sentencia que se considera injusta. ${ }^{40}$

\footnotetext{
38 Ibidem.

39 El informe del Procurador General de la Corte Suprema don Nicolás Eduardo Becerra en el Caso "Olmos", Sección V.

40 El Fallo "Lanci" usa la expresión arbitrario, mientras que el Fallo "Olmos" (voto de mayoría) emplea la voz ilógico. Fallo "Lanci” de la Corte Suprema de Justicia argentina, extraído de Carrió, Alejandro D., ob. citada, p. 140.
} 
Por último, se ha indicado que considerando que los medios de impugnación, previstos por la ley procesal y garantizados por la Constitución, encuentran su "ratio iuris" en el derecho del justiciable a provocar la revisión de una resolución judicial en "su defensa" y "beneficio" a los fines de obtener una decisión más justa, admitir que el empleo de un recurso jurisdiccional tendrá por resultado un mayor perjuicio para el recurrente es, sin más, autorizar el ilógico resultado de contradecir la teleología propia de toda articulación recursiva. Si se admitiera la alteración de este límite en el Tribunal de reenvío se haría depender la interposición del recurso por inobservancia de formas procesales o la violación de las reglas del buen pensar, no ya de la existencia de un interés legítimo (el agravio) ni de la existencia efectiva de vicios in cogitando o in procedendo, sino de una valoración estimativa, de cálculo contingente, sobre el futuro resultado del nuevo juicio. $^{41}$

b) Exclusión de la lógica de ganar para perder. Se pretende evidenciar, con este argumento, lo ilógico que resulta aceptar que el acusado pueda recurrir y correr el riesgo de verse perjudicado por su propia actividad recursiva. Así es como se señala que carece de razonabilidad pensar que se pueda "ganar para perder", o sea que el condenado, único recurrente, gane su recurso, logre la anulación de la condena en su contra, consiga un nuevo juicio y, como paradójico resultado de su triunfo, vea empeorada su situación inicial, pues la nueva condena terminará siendo más grave que la anulada, gracias a su exclusivo impulso. ${ }^{42}$

\footnotetext{
41 Sent. No 118 del 07/11/2002, Autos: "Monasterio Santa Catalina de Sena c/ Omar García López y otro", Ordinario, Recurso de Casación". Magistrados: Dres. Kaller Orchansky, Sesín y Cafure de Battistelli, Tribunal Supremo de Justicia de Córdoba. En idéntico sentido se pronuncia la Sala III del Tribunal de Casación Penal de la Provincia de Buenos Aires, señala que si se aceptase que en el nuevo juicio no es aplicable la prohibición de reformatio in peius se haría depender la interposición del recurso por inobservancia de formas procesales, no ya de la existencia de un interés legítimo, ni de la existencia de vicios "in procedendo", sino de una valoración estimativa sobre el resultado futuro del nuevo juicio, convirtiendo al sistema de las impugnaciones penales en una arena movediza de dudas e inestabilidad jurídica. Acuerdo de la Sala III del Tribunal de Casación Penal, de la Provincia de Buenos Aires, integrada por los ministros don Ricardo Borinsky, don Carlos Alberto Mahiques y don Benjamín Ramón Sal Llargués, Ciudad de la Plata, Provincia de Buenos Aires, 15 de abril de 2004, causa número 1.931 (registro de presidencia número 9.642), caratulada “A. A., S. M. s/recurso de casación.

42 Moción parlamentaria de miembros de Partido Unión Cívica Radical. Ver página Web: http://www.bloqueucr.gov.ar/proyectosVer. $\mathrm{N}^{\circ}$ de Expediente 6388-D-2006, Trámite Parlamentario 160, Sumario: Código Procesal Penal. Modificación del articulo 445, sobre competencia del tribunal de alzada, aplicación de la garantía de la "reformatio in peius" en el nuevo juicio en el caso del condenado recurrente exclusivo. Firmantes: Aguad, Oscar Raúl, Becanni, Alberto Juan, Romero, Rosario Margarita y Oliva, Cristian Rodolfo. Se debe mencionar que existe un Proyecto de Código Procesal Penal para la Nación Argentina, preparado por el INECIP (Instituto de Estudios Comparados en Ciencias Penales y Sociales creado en 1989, en el que participan, entre otros, David Baigún, Alberto Binder y Julio Maier) que contiene una norma similar (art. 343). Asimismo, existe un Proyecto de Código Procesal Penal para la Provincia de Chubut (art. 387) en el mismo sentido.
} 
c) Ejercicio libre y tranquilo del derecho a recurrit. Este argumento parte de la idea fundamental que la prohibición de la reformatio in peius reposa en la necesidad de garantizar al imputado la libertad y tranquilidad de recurrir. El libre ejercicio del derecho al recurso sólo existe cuando el condenado está completamente seguro que el recurso que intentará nunca podrá perjudicarlo más que la propia sentencia condenatoria recurrida, siempre que estemos frente a ausencia de actividad recursiva del acusador.

La existencia de algún peligro consistente en la posibilidad de que la impugnación deducida sólo en su favor pudiera terminar empeorando su situación, importaría además un serio condicionamiento al derecho al recurso contra una sentencia condenatoria, lo que desnaturalizaría su contenido y alcances. $^{43}$

En su voto particular el Juez Dr. Petracchi, quien sostiene que en el nuevo juicio la sentencia que de él resulte tiene el límite de la prohibición de la reformatio in peius, señala que la aceptación del argumento del "resultado o riesgo previsible" es incompatible con el reconocimiento del derecho al recurso en los términos del art. 8, $\mathrm{N}^{\circ}$ 2, letra h, de la Convención Americana sobre Derechos Humanos. Afirma que si el ejercicio de tal facultad supusiera el riesgo de empeorar la propia situación, ella ya no podría ser ejercida libremente y que la existencia de este "riesgo" lesionaría el derecho de defensa, en la medida en que plantea la posibilidad de que el imputado prefiera asumir las consecuencias injustas de una sentencia coaccionado por el temor de que ellas se agraven aún más. ${ }^{44}$

d) Subsistencia de la sentencia anulada. Al contrario de lo que aseveran los promotores de la tesis opuesta, quienes abogan por esta tesis señalan que los efectos de la nulidad no son absolutos, esto es, no privan al acto anulado de todos sus efectos.

Se sostiene que la nulidad de la resolución no implica la eliminación del acto sentencial sino sólo la privación de sus efectos normales o inmediatos, quedando subsistentes otros efectos, tales como los límites que impondrá a la futura decisión que recaiga en reemplazo de la anulada. ${ }^{45}$ En efecto, la nulidad como categoría jurídica- importa la declaración de invalidez de un acto para producir ciertos efectos jurídicos, pero no conlleva a la inexistencia del acto, como si nunca se hubiera realizado. Por el contrario, aún declarada la nulidad de un acto sentencial, subsiste el efecto prohibitivo para el Tribunal de recurso (originario o derivado) de la "reformatio in peius". El instituto en cuestión tiene plena vigencia cualquiera sea el Tribunal de recurso de que se trate, sea éste el Tribunal de primer

\footnotetext{
43 Ibidem.

${ }^{44}$ Voto particular del Dr. Enrique Santiago Petracchi, Fallo "Olmos", p. 7.

${ }^{4}$ De La Rúa, F., "Límites de los recursos. La prohibición de reformatio in peius en materia penal y civil”, ob. citada, p. 230. De La Rúa se hace cargo de la distinción entre inexistencia y nulidad siguiendo en esto a J. Maier que la formula en una obra sobre la función normativa de la nulidad.
} 
Barrientos - Prohibición de reformatio in peius...

grado, la Cámara de Apelación o el propio Tribunal Superior de Justicia. El principio debe ser necesariamente acatado por el juzgador de recurso desde que así lo impone el sistema procesal vigente. El instituto referido no responde sólo a su regulación procesal específica, sino que también encuentra inspiración y sustento en la propia Ley Suprema de la Nación, que garantiza el derecho de defensa en juicio (art. $18 \mathrm{CN}){ }^{46}$

También se sostiene que la naturaleza derivada del juicio de reenvío determina que no pierda toda su importancia la resolución impugnada, aunque sea anulada, sino que se conserva en el curso ulterior del proceso, en cuanto el imputado no debe ser tratado peor que en el primer fallo, y todas las nuevas resoluciones deben ser dictadas dentro del marco de la primitiva. ${ }^{47}$

e) El límite de la jurisdicción está determinado por el interés del recurrente. Incluso quienes pueden no aceptar la idea de la subsistencia de la sentencia anulada para imponer límites a la decisión futura que recaiga en reemplazo de la anulada arguyen que, un medio que la ley ha dado para favorecer al imputado no puede admitirse que luego se retuerza en su perjuicio. Y si bien se puede sostener que la prohibición sólo se puede verificar en relación a una sentencia existente, y no, respecto de una que no existe más en razón de la anulación, el reexamen se debe limitar a la medida del interés de la parte que llevó el recurso, y así como una impugnación sin interés deviene inadmisible, tampoco se puede admitir que la impugnación del imputado pueda provocar un resultado lesivo para su propio interés. ${ }^{48}$

f) Limitación jurisdiccional en el nuevo juicio (cosa juzgada y ne bis in ídem). Según el Juez don Enrique Santiago Petracchi de la Corte Suprema argentina, el argumento que afirma que la naturaleza del juicio oral impone la devolución completa de la jurisdicción al tribunal de reenvío, es insostenible por varias razones. Primero, pues respecto a la fijación de la pena, la situación en un juicio oral no difiere sustancialmente de la que se presentaría en un procedimiento escrito. Aún en el marco del reenvío en un procedimiento escrito, el juez no está eximido de conocer personalmente al futuro condenado. En tales condiciones, podría suceder como consecuencia de dicha audiencia, o bien, por cualquier otra modificación de las condiciones personales, que el sentenciador se convenciera de la necesidad de imponer una pena mayor, sin embargo, no podría hacerlo.

\footnotetext{
46 Sent. No 118 del 07/11/2002, Autos: "Monasterio Santa Catalina de Sena c/ Omar García López y otro - Ordinario- Recurso de Casación", citado.

47 Acuerdo de la Sala III del Tribunal de Casación Penal, de la Provincia de Buenos Aires, 15 de abril de 2004. Se cita a De la Rúa, F., La Casación Penal, ob. citada, 1994, p. 272.

48 Ibidem. Cita a De la Rúa, F., La Casación Penal, ob. citada, pág. 273; S.C.B.A. Ac. 31.369, voto del ministro Lozano Baudón y sus citas de Cafferata Nores y el propio De la Rúa. También se cita sentencia de la Cámara de Apelación en lo Penal de Morón, Sala II, causa "Ferradas" del 9 de abril de 1987.
} 
Segundo, cuando el acusador no ha recurrido la sentencia de condena, ella queda firme no sólo "a su respecto", sino también respecto de los tribunales de alzada, que carecen de jurisdicción para modificarla. Tal imposibilidad, de raíz constitucional, no podría ser eludida por la vía de la "declaración de nulidad". En consecuencia, dicho obstáculo tampoco podría ser sorteado por el tribunal de reenvío, cuya jurisdicción también queda restringida por la cosa juzgada parcial. La existencia de límites, por lo demás, en nada puede sorprender, pues ella hace a la naturaleza misma del debate. Así, el tribunal de juicio nunca tiene una “jurisdicción ilimitada”, sino que, por el contrario, el pronunciamiento de condena no puede exceder el marco de la acusación. ${ }^{49}$

Tercero, la realización de un nuevo debate como consecuencia del recurso del imputado se convertiría en el instrumento para producir una grosera violación del non bis in ídem: no sólo se lo somete nuevamente a juicio, sino que además, el Estado aprovecha la ocasión para imponerle más pena. ${ }^{50}$

La Corte Suprema de Costa Rica en fallo del año 1998, pronunciándose sobre recurso de casación en que se impugnaba la sentencia del segundo juicio por infracción a la prohibición de la reformatio in peius, dijo que, considerando que el Fiscal de Ministerio Publico había restringido su recurso de casación contra la sentencia del primer juicio a aspectos de fondo relativos a uno solo de los delitos que se imputaba a los acusados (delito de violación de morada), debía entenderse que se había conformado con la pena impuesta respecto al delito de violación (ataque sexual). ${ }^{51}$

\footnotetext{
49 En este sentido también la Corte Suprema de Costa Rica en Exp: 05-000225-006-PE Res: 200601047, Sala Tercera, 23 de octubre de 2006, en que afirma que: "Tampoco le asiste razón al Ministerio Público al sugerir, según parece entenderse de su libelo, que al sentenciado se le podrían imponer los mismos doce años de prisión acordados en el fallo, por hallarse dentro de los límites del marco penal que contemplaba dicha ley. Esto no es jurídicamente posible, pues el error en la aplicación de la ley sustantiva que aquí se observa es en realidad tan simple como que los jueces supusieron la existencia de tres delitos independientes, cuando en verdad se trataba de uno solo. Puesto que ya se hizo uso de la facultad de disminuir la pena mínima a la mitad, resulta evidente que en un juicio de reenvío no podría el nuevo Tribunal ignorarla y decidir, por ejemplo, que establecerá ocho años de pena privativa de libertad para el único delito (el extremo mínimo que preveía la ley aplicada en la especie, o bien los cinco años que también como límite mínimo determinó otra ley posterior). El uso de la facultad discrecional de disminuir dicha pena creó una situación jurídica consolidada que de ningún modo puede revertirse, si se está en presencia del reclamo hecho a favor del justiciable, pues de otro modo se conculcaría flagrantemente la prohibición de reforma en perjuicio". (Subrayado del autor).

${ }^{50}$ Voto particular Dr. Enrique Santiago Petracchi, Fallo "Olmos", p. 8.

51 Corte Suprema de Justicia de Costa Rica, V. 320-98, Sala Tercera, San José, 30 de marzo de 1998. En el primer juicio los acusados fueron condenados a la pena de 5 de años en su condición de cómplices. Contra la primera sentencia los acusados recurrieron de casación. Dicho recurso fue acogido, ordenando el tribunal de alzada la realización de nuevo juicio. La sentencia del segundo juicio impuso a los mismos acusados, que habían recurrido, la pena de 12 años por el delito de violación. Contra esta sentencia los acusados perjudicados con el empeoramiento de su situación procesal dedujeron nuevamente recurso de casación.
} 
La Corte costarricense interpretó la inactividad recursiva del Ministerio Público como conformidad con lo resuelto en el primer juicio respecto del delito de violación, por lo que no dudó en declarar que aquello significaba que los impugnantes sí quedaron en este asunto protegidos por dicho principio (prohibición de reforma en perjuicio), el cual debió ser aplicado de acuerdo con las circunstancias, ya sea que se hubiese dado el reenvío o que ahora la propia Sala se pronuncie sobre el fondo. En el primer caso el Tribunal de mérito al sustanciar nuevamente la causa puede variar la calificación de los hechos y el grado de participación de los acusados, pero cuando ello ocurre, como en el sublite, es obligación de los jueces respetar esta garantía. ${ }^{52}$

g) El juicio de reenvío no es un juicio nuevo y originario. Quienes sostienen este argumento parten de la premisa de que el nuevo juicio es consecuencia de la declaratoria con lugar del recurso interpuesto a favor del imputado. ${ }^{53} \mathrm{O}$ dicho de otro modo, la sentencia de reenvío no remite a la situación anterior al fallo anulado, sino que es tributaria del que lo anuló. ${ }^{54}$

Para llegar a esta conclusión, se parte tanto de la aplicación de la regla de limitación jurisdiccional a los puntos a los cuales se refirieron los agravios, como de la prohibición de la reformatio in peius. Así, se dice que sí ambas reglas mantienen su influencia hasta el momento mismo del fallo rescisorio, es acertada la afirmación de que el juicio de reenvío no constituye un procedimiento originario o nuevo, y se encuentra vinculado al juicio originario a través del procedimiento impugnativo que culminó en la anulación, en razón de tratarse de la misma causa que ha sido decidida y debe volverse a decidir con criterio integrativo complementario de la sustitución. ${ }^{55}$

La Sala Constitucional de la Corte Suprema de Costa Rica, en sentencia dictada con fecha 14 de diciembre 2005, sobre acción de inconstitucionalidad

52 Ibidem. El mismo fallo cita a Núñez, Ricardo C., Código Procesal Penal de la Provincia de Córdoba, Lerner, 1978, pp. 466 y 467, y a Clariá Olmedo, Jorge A., Tratado de Derecho Procesal Penal, Ediar. 1963. T. IV, pp. 274 y 275.

${ }^{53}$ Corte Suprema de Justicia de Costa Rica, Voto No 1026-97, Sala Tercera, San José, 25 de septiembre de 1997. En sentencia de la misma Corte dictada 20 de enero de 2006, en Exp: 04-000555-0006 -Pe Res: 2006-00011 Sala Tercera reitera su doctrina invariable: "Conforme a los artículos 416 y 417 del Código Procesal Penal, al anularse en revisión una sentencia se remite a nuevo juicio cuando el caso lo requiera o se pronuncia directamente la sentencia que corresponda en derecho. En este asunto, un juicio de reenvío para discutir sobre la fijación de la pena es evidentemente inútil, por las siguientes razones: a) al no ser atendible un recurso del ministerio público, la pena en ningún caso podría ser superior a los cinco años de prisión que le impuso el tribunal de juicio (prohibición de la reforma en perjuicio o non reformatio in peius, artículos 417 párrafo segundo, 432 y 451 del Código Procesal Penal)".

54 Acuerdo, Sala III del Tribunal de Casación Penal, de la Provincia de Buenos Aires, 15 de abril de 2004. Se cita en el acuerdo a Almeyra, Miguel Ángel, "La reformatio in peius y el juicio de reenvío" en Doctrina Judicial, Revista La Ley, Buenos Aires, II, 25.1.

55 Ibidem. El tribunal reconoce que hace una cita prácticamente textual de Clariá Olmedo, J.A., Tratado de Derecho Procesal Penal, Tº. VII, p. 272. 
promovida contra los artículos 450 y 451 del Código Procesal Penal ${ }^{56}$, sostuvo que: 'De la simple lectura de las normas, resulta evidente que el juicio de reenvío al que ellas se refieren es resultado del hecho de que el recurso de casación haya sido declarado con lugar, provocando la anulación total o parcial de la resolución impugnada. Por ende, no estamos ante la hipótesis de que se pretenda modificar lo resuelto en un fallo que ya haya adquirido autoridad de cosa juzgada material, puesto que éste aun no habría adquirido ese carácter. Antes bien, el nuevo debate que se suscite se producirá en el marco del mismo proceso penal que dio lugar al pronunciamiento anulado y no de otro distinto". ${ }^{57}$

h) La supervivencia del proceso es de naturaleza puramente defensiva por la inactividad recursiva del Ministerio Público. Si la sentencia se anula sin recurso fiscal, en razón de la conformidad del Ministerio Público el ejercicio de la acción penal pública cesa con la aquiescencia del ente persecutor y la supervivencia del proceso en razón del recurso del imputado se encuentra despejado de toda actividad persecutoria sustancial y consiste en pura actividad defensiva. ${ }^{58}$

Asimismo, se dice que si se admitiera que, como resultado de la interposición de un recurso, el imputado pudiera enfrentar una situación peor que la gozada antes, se llegaría a la conclusión ilógica de que el ejercicio de esa actividad defensiva tendría -por sus efectos- virtualidad acusatoria. ${ }^{59}$

i) Objeto defensivo de los recursos. Para la defensa, la finalidad específica de los recursos es la obtención de una ventaja o un resultado más favorable para el imputado. En este sentido cuando el recurso se interpone por la defensa el objetivo no es otro que obtener la modificación de la sentencia en su favor, sin correr ningún riesgo.

Si esa finalidad es un aspecto esencial del contenido del derecho al recurso $\mathrm{y}$ de su ejercicio, en cuanto pone en marcha el control jurisdiccional de las decisiones de los tribunales inferiores, no es aceptable que con motivo de un recurso y a falta de impugnación del Ministerio Público, se pueda agravar,

\footnotetext{
56 El artículo 451 del Código Procesal de Costa Rica expresa: "Cuando el recurso ha sido interpuesto sólo por el imputado, o en su favor, en el juicio de reenvío no se podrá imponer una sanción más grave que la impuesta en la sentencia anulada, ni desconocer los beneficios que en esta se hayan acordado". Por su parte, el art. 413 CPP de Bolivia, párrafo tercero, expresa: "Cuando el recurso haya sido interpuesto sólo por el imputado o, en su favor, en el juicio de reenvío no se podrá imponer una sanción más grave que la impuesta en la sentencia anulada, ni desconocer los beneficios que en esta se hayan otorgado".

${ }^{57}$ Ver: Exp: No 05-014348-0007-CO Res: No 2005-17195.

58 Acuerdo, Sala III del Tribunal de Casación Penal, de la Provincia de Buenos Aires, 15 de abril de 2004. Se cita en el fallo a De La Rúa, F., La Casación Penal, ob. citada, pp. 274 y 275

${ }^{59}$ Ibidem. Este argumento es de De La Rúa, según lo señala la propia sentencia y se puede leer en "Límites de los recursos y prohibición de reformatio in pejus en materia penal y civil", ob. citada.
} 
Barrientos - Prohibición de reformatio in peius...

perjudicar o empeorar la situación del recurrente, contrariando precisamente el objeto defensivo del recurso. ${ }^{60}$

\section{CONSIDERACIONES QUE PERMITEN OPTAR POR LA TESIS DE LA MAXIMIZACION DE LA EFICACIA DEL DERECHO AL RECURSO}

Las consideraciones que a continuación desarrollaré son de dos tipos. Las primeras, constituyen un resumen de las razones o reflexiones que hacen que me incline por la tesis de la maximización de la eficacia del derecho al recurso. Las segundas, son deducciones derivadas de una lectura finalista -más de alguno dirá, garantista- de las normas del Código Procesal Penal.

\section{Razones adicionales para propugnar la mayor eficacia del derecho al recurso.}

Me inclino por la "tesis de la maximización de la eficacia del derecho al recurso" por las siguientes razones adicionales:

a) Subsistencia del fallo anulado. Quienes se oponen a la idea que el fallo anulado conserve efectos para limitar la jurisdicción del tribunal de reenvío fundados en la inexistencia radical de dicho fallo, olvidan que cuando la Corte, conociendo un recurso de nulidad, anula una sentencia y dicta una de reemplazo, al hacer esto último está obligado a considerar los límites derivados de la sentencia que se anuló, uno de los cuales es la prohibición de imponer una pena más grave si el acusado es el único recurrente. Estamos pues, en este caso, en presencia de una sentencia anulada cuyos efectos subsisten con el objeto de limitar el poder jurisdiccional-punitivo del Estado.

Esta supervivencia de la sentencia anulada, para los efectos de limitar al tribunal de alzada, no difiere en nada de la que se predica respecto de la supervivencia del fallo anulado cuando lo que se pretende es limitar al tribunal de reenvío. En ambos casos, y esto conviene tenerlo en cuenta, la nulidad del fallo se produce por iniciativa del acusado, como asimismo la sentencia de reemplazo y la sentencia del tribunal de reenvío están directamente vinculadas a la resolución que acogió el recurso.

Además, la subsistencia del fallo anulado, en cuanto límite tanto para el tribunal de alzada como para el tribunal de reenvío, es consecuencia de la consolidación de la situación procesal del acusado, cuando el Ministerio Público no ha ejercido su facultad de impugnar y se ha conformado con lo resuelto en el

${ }^{60}$ Ibidem. 
primer juicio. Esta supervivencia de efectos es un corolario de la cosa juzgada parcial respecto del interviniente que no ha recurrido. ${ }^{61}$

La seguridad jurídica, dimanante de la sentencia pasada en autoridad de cosa juzgada, resultaría relegada si no se respetan los derechos adquiridos surgidos de la sentencia objeto del recurso, que es impugnada no para perder lo obtenido, sino que para ganar lo no concedido.

b) Aprovechamiento o enriquecimiento procesal injusto. La no interposición de recurso de parte del Ministerio Público, pudiendo ejercer la facultad de impugnar, implica la conformidad del ente persecutor con la sentencia dictada. Aceptar que el recurso del acusado, frente a la inactividad fiscal, pueda tener virtualidad acusadora, implicaría aceptar que el Ministerio Público, a pesar de su pasividad, pueda aprovecharse de la diligencia del acusado y su defensa e intentar en un nuevo juicio, con la experiencia obtenida, la imposición de una pena más grave que la impuesta en el primer juicio. Eso supondría no sólo una burla del sistema procesal a los justiciables, sino una especie de enriquecimiento o aprovechamiento procesal sin causa o injusto de parte del Ministerio Público. Equivaldría a sostener que existe, por mandato legal, una autorización para quebrantar el principio de buena fe procesal.

c) Necesidad de promover determinados valores jurídicos comprometidos en la persecución penal. Las ideas expresadas en las letras precedentes requieren que se promuevan los valores que están en juego en el proceso penal, tales como la dignidad de la persona humana, la legitimidad del poder punitivo y la seguridad jurídica.

Los valores mencionados se realizan en un sistema procesal que asegure la posibilidad cierta y efectiva de recurrir a un tribunal para que resuelva una determinada pretensión jurídica. Un sistema que no asegura efectivamente el ejercicio del derecho a recurrir no sólo es deficitario en el respeto a la dignidad, en cuanto mira al hombre sólo como un medio y no como un fin en sí mismo, y

\footnotetext{
${ }^{61}$ Meins O., Eduardo, "El debido proceso en el ordenamiento jurídico chileno y en el Nuevo Código de Procedimiento Penal", Revista Ius et Praxis, Universidad de Talca, Chile, Vol. 5, N 001 , año 1999, p. 456. Este autor señala que "la reformatio in peius [...] vulnera la institución de la cosa juzgada, pues si sólo recurre contra una resolución judicial condenatoria el imputado, dicha resolución se encuentra firme o ejecutoriada respecto del titular de la acción penal". J. Maier sostiene que: "Por ejemplo, si el funcionario que representa al ministerio público en el procedimiento omite interponer algún recurso contra una decisión, de su parte la decisión quedado firme;...", Derecho Procesal Penal, Tomo II, Sujetos Procesales, Editores del Puerto, Buenos Aires, 2004, $1^{a}$ edición, $1^{a}$ reimpresión, p. 332. En el Tomo I de su obra J. Maier señala que: "Como se concibe la cosa juzgada parcial, el fallo recurrido queda firme en todo aquello que no constituye materia del agravio expuesto en el recurso. Así se logra la seguridad jurídica del recurrente, quien conoce que, a salvo la facultad de otros intervinientes para recurrir, su recurso fijará el thema decidendum y no atribuirá al tribunal del recurso una posibilidad cognoscitiva más amplia que la puesta por él en juego". Derecho Procesal Penal, Tomo I, ob. citada, p. 593.
} 
Barrientos - Prohibición de reformatio in peius...

carece por ello de legitimidad, en cuanto vulnera la prohibición de imposición de pena sin un juicio previo con todas las garantías, sino que lo es también en la provisión de seguridad jurídica, que impone al Estado el deber de respetar y asegurar la inviolabilidad de los derechos fundamentales, no sólo mediante una declaración normativa de la mayor jerarquía sino que por sobre todo mediante el goce efectivo de tales derechos.

Si el Derecho tiene entre sus funciones, según J. Habermas, la estabilización de las expectativas de las personas, la seguridad jurídica, entendida como certeza de que una situación jurídica no será modificada más que por procedimientos regulares y autoridades competentes previamente establecidas, no es sino el catalizador de dicha función, en cuanto a través de aquélla, pueden las personas prever las consecuencias de sus acciones en un ambiente que, a su vez, propicia el mayor grado de autonomía personal.

El principio nec reformatio in peius, integrante del debido proceso, contribuye al desarrollo del principio de seguridad jurídica, puesto que protege al recurrente en la situación jurídica adquirida, brindándole confianza y certeza respecto de sus derechos y promoviendo el acceso a la jurisdicción de revisión en un accionar libre y desprovisto de peligros.

d) Efecto contradisuasivo de la prohibición de la reformatio in peius. La imagen de los concursos de $\boldsymbol{T V}$. Nos preguntamos al inicio de este trabajo en qué casos el efecto contradisuasivo de la prohibición de la reformatio in peius tiene sentido.

A estas alturas del trabajo la respuesta es que el efecto contradisuasivo de la prohibición también debe operar cuando lo que se pide es la realización de un nuevo juicio. No es razonable que en este caso el acusado tenga que decidir entre quedarse con lo ganado (aunque le resulte insatisfactorio), por temor a perderlo si ejecuta una acción adicional (interposición de recurso), o arriesgar todo o una parte importante de lo obtenido pero con la expectativa de obtener la absolución. Esta disyuntiva se parece a la que enfrentan algunos concursantes de programas de TV, los que llegado un momento deben elegir entre retirarse e irse a casa con poco dinero pero seguro, o bien, arriesgarse a irse sin nada de dinero o con una cantidad muy ínfima y seguir en el concurso para ganar el premio mayor. Esta lógica de concurso de TV no se puede aplicar al proceso penal, donde están comprometidos muchos valores y bienes jurídicos, pero por sobre todo donde está comprometida la obtención de la verdad.

La lógica del concurso de TV, que no es sino la del riesgo lúdico y del rating, es buena para esos fines. La lógica que, por el contrario, debe informar las instituciones procesales, como los medios de impugnación, es la lógica de la libertad y de la seguridad jurídica. En el proceso penal, a diferencia del concurso de TV, no se trata, como es obvio, de ganar o perder una determinada cantidad de dinero, lo que se busca es el mayor grado de acercamiento al ideal de justicia y una 
condición imprescindible para lograr esa mayor proximidad es la libertad para recurrir sin arriesgar. Definitivamente la certeza jurídica no es compatible con la imagen del concurso de TV.

e) El traslado del riesgo peyorativo al acusado constituye una coacción ilegítima que afecta la actividad recursiva. En una sociedad pretendidamente democrática y liberal el Estado no debe trasladar el riesgo peyorativo a los ciudadanos. En el proceso civil y penal, a diferencia de los concursos, el afectado con una resolución adversa debe tener siempre la más absoluta libertad para decidir si recurre o no, sin arriesgar nada. Si el acusado o su defensa, para tomar la decisión de alzarse contra una sentencia, requieren hacer un cálculo de posibles riesgos, entre los cuales pueden estar el aumento de la pena o la pérdida de un beneficio concedido, debemos concluir que no gozan de plena libertad para recurrir. Si en definitiva, deciden no recurrir y conformarse con una sentencia que siendo desfavorable no es completamente adversa, porque ha existido una recalificación de los hechos, se ha acogido una atenuante o se ha concedido un beneficio, etc.; estamos en una situación de disuasión producida por el temor de perder lo obtenido. ¿No equivale esto a la actitud del concursante que se retira con poca plata pero segura? ¿Es raro que un acusado y su defensa se encuentren en esta situación cuando su única alternativa es la de recurrir de nulidad y solicitar la realización de nuevo juicio? ¿Por qué no debería ser aplicable a este caso la prohibición de la reforma en perjuicio?

La reforma en perjuicio del acusado, cuando éste es el único recurrente y pide la anulación del juicio oral, implica aceptar que esa contingencia - la reforma peyorativa - se constituya legítimamente en un freno al ejercicio del derecho al recurso. En tal caso, la eventualidad de reformatio in peius actúa como instrumento de coacción que vicia la voluntad del justiciable en relación a una actuación procesal tan significativa como es la promoción de medios impugnativos.

f) Adaptación de la prohibición de la reformatio in peius al nuevo proceso penal. La comprensión del nuevo sistema de recursos en el procedimiento acusatorio, impone una readecuación de la prohibición de la reformatio in peius. Parece de sentido común advertir que si la tranquilidad para recurrir que la prohibición de la reformatio in peius pretende asegurar (lo que llamamos efecto contradisuasivo), quedara circunscrito sólo a que el tribunal de nulidad no agrave por su propia sentencia la situación del condenado recurrente exclusivo, pero no alcanzará a la que pueda dictarse en el posterior juicio de reenvío, tal tranquilidad no existiría, pues siempre existirá la posibilidad de que su recurso termine resolviéndose en su contra, agravando la pena impuesta en la condena recurrida.

Al perder centralidad la apelación como medio de impugnación, y quedar disponible el recurso de nulidad, cuyo efecto, por regla general, es la nulidad de la sentencia y del juicio, es absolutamente lógico y necesario pretender que las instituciones que potencian el derecho a recurrir, como es el caso de la interdicción de la reforma en perjuicio, sean adaptadas a las nuevas condiciones del 
Barrientos - Prohibición de reformatio in peius...

proceso penal. De lo contrario, se corre el riesgo que una garantía que forma parte del núcleo esencial del derecho al recurso tenga una aplicación marginal, privando de eficacia al único medio de impugnación disponible: el recurso de nulidad.

g) Interpretación finalista de las normas del Derecho Procesal Constitucional. Aplicación del principio pro homine. Las normas que regulan lo concerniente al derecho al recurso, en la medida que éste es un derecho constitucionalizado, integran lo que se denomina Derecho Procesal Constitucional, cuya interpretación debe hacerse con instrumentos hermenéuticos más sofisticados que los contemplados en el Código Civil.

$\mathrm{Si}$, por un lado, la finalidad de los recursos, en cuanto herramienta puesta a disposición de la defensa, es la modificación de la situación procesal del acusado en su favor y, por otro, la finalidad de la prohibición de la reformatio in peius es evitar que aquel sea disuadido de presentar un recurso por temor a empeorar esa situación, perdiendo lo ya obtenido, es de toda lógica interpretar las normas que se refieren a estas instituciones (los recursos y la prohibición) de forma tal de lograr el mayor rendimiento de ellas, esto es, de alcanzar el mayor cumplimiento de las finalidades a que están dirigidas. ${ }^{62}$

Para hacer realidad la racionalidad instrumental de la ley procesal, toda interpretación debe considerar el telos de las instituciones procesales, pues de lo contrario dicho ejercicio hermenéutico adolecería de consistencia lógica. Lo anterior supondría que, estando unas instituciones procesales determinadas destinadas a cumplir una función-fin, por aplicación de un criterio de interpretación que no considere (o sea incompatible con) esa racionalidad instrumental y la funcionalidad consecuente, en definitiva, dichas instituciones no cumplan, o lo hagan sólo parcialmente, la función-fin para la que fueron ideadas. ${ }^{63}$

Creo que el principio pro homine o pro libertatis, como criterio interpretativo, que exige procurar la alternativa más beneficiosa para las personas y sus derechos esenciales, o la que restringe en menor grado esos derechos, es más congruente con la funcionalidad y finalidad de las instituciones procesales que analizamos y arroja como resultado una mayor eficacia de ellas. ${ }^{64}$ Lo dicho, equivale a afirmar que si lo que se considera es la "teleología propia de la articulación recursiva", en la que encaja, en forma exacta, la prohibición de la reforma peyorativa, en cuanto instrumento de aseguramiento y eficacia del derecho al recurso, la única forma de

\footnotetext{
62 Sobre la aplicación de un criterio finalista en el ámbito del derecho a los recursos, ver: Fernández Segado, Francisco "El Derecho a la Jurisdicción y las Garantías del Proceso Debido en el Ordenamiento Constitucional Español”, Revista Ius et Praxis, Universidad de Talca, Año 5, N 1 , 1999, especialmente pp. 84-89.

${ }^{63}$ Un análisis sobre la racionalidad instrumental de la ley procesal se puede encontrar en Taruffo, Michele, "Racionalidad y Crisis de la Ley Procesal", $D O X A \mathrm{~N}^{\circ} 22$, año 1999, pp.311-320.

${ }^{64}$ En cuanto al principio pro homine, consultar: Nogueira Alcalá, Humberto, "Las Constituciones y los Tratados en materia de Derechos Humanos: América Latina y Chile", Revista Ius et Praxis, Universidad de Talca, Año 6, N², 2000, especialmente pp. 214-243.
} 
lograr la alternativa más beneficiosa para las personas y sus derechos, es elevar el fin de la norma como directriz hermenéutica por sobre cualquier otro elemento. ${ }^{65}$

A nuestro juicio, la mera aplicación del elemento gramatical por sobre la finalidad de la institución, no satisface la racionalidad instrumental de la norma procesal que establece la prohibición de reforma peyorativa en nuestro ordenamiento, ni el fundamento político de la garantía.

\section{Consideraciones derivadas de una lectura finalista del Código Procesal Penal. La prohibición de la reformatio in peius integra las disposiciones generales aplicables a los recursos. Posible caso de inconstitucionalidad.}

Es necesario recordar la ubicación del art. 360 del CPP en las disposiciones generales aplicables a los recursos. Esto, de manera simple, significa que dicha disposición se aplica a todos los recursos procesales. Es decir el acusado recurrente único, sea de apelación o de nulidad, está cubierto por la garantía de la interdicción de la reformatio in peius.

Recordemos también que la regla general es que acogido un recurso de nulidad se producirá la nulidad del juicio y de la sentencia, por lo que es necesario inquirir por la extensión de la garantía comentada. El art. 360 del CPP señala que la Corte no podrá reformar la sentencia en perjuicio del recurrente, con lo que pudiera entenderse que la garantía se aplica sólo en aquellos casos en que es la Corte la que resuelve mediante sentencia de reemplazo, que como hemos dicho son dos: cuando se apela y cuando, habiéndose recurrido de nulidad, se aplica el art. 385 del CPP; esto es, las situaciones que legislativamente se establecieron como excepcionales.

Resulta curioso que el legislador establezca una garantía en las disposiciones generales a todos los recursos, y que dicha norma termine aplicándose a los casos excepcionales ${ }^{66}$. Creo que a este respecto existen dos alternativas.

a.i) Primera alternativa: La primera vía consiste en buscar un criterio hermenéutico que le de mayor utilidad a la norma citada, más acorde con la finalidad de la garantía (el llamado efecto contradisuasivo). En este sentido, se puede sostener que si la finalidad de la prohibición de la reformatio in peius es evitar que el acusado, a quien se ha condenado, se disuada de recurrir por temor a una

\footnotetext{
${ }^{65}$ Una expresión clara de un criterio finalista se encuentra en el art. 3 del Código Procesal Civil de Colombia que señala: “Al interpretar la norma procesal, el juez deberá tomar en cuenta que la finalidad de aquéllas es dar aplicación a las normas de fondo. En caso de duda, podrá acudir a los principios generales del Derecho."

${ }^{66} \mathrm{El}$ profesor Raúl Tavolari sostiene que recurrida por el imputado una sentencia, acogida que sea la impugnación, excepcionalmente se autorizará al Tribunal Superior que pronuncie sentencia de reemplazo. Tavolari, Raúl, "Informe en Derecho sobre Recurso de Nulidad publicado", en Boletín del Ministerio Público N³, de julio de 2001, p. 42.
} 
Barrientos - Prohibición de reformatio in peius...

pena mayor, ella es condición necesaria del ejercicio del derecho al recurso, tanto si se pide la nulidad de la sentencia y la dictación de una sentencia de reemplazo como si se pide la nulidad de la sentencia y la realización de un nuevo juicio (juicio de reenvío). Podríamos decir entonces que, donde existe la misma razón debe existir la misma disposición.

Si el acusado, único recurrente, (1) invoca errónea aplicación del derecho y estamos en algunos de los caso del art. 385, y la Corte (Suprema o de Apelaciones) anula la sentencia, ésta por mandato del art. 360 no podrá imponer una pena más severa que la impuesta por la sentencia anulada. No se aprecia ninguna razón para sostener que, cuando existe (2) juicio de reenvío (realización de nuevo juicio) el nuevo tribunal no esté igualmente limitado por la prohibición de la reforma en perjuicio, puesto que de lo contrario estaríamos en presencia de una discriminación que no tiene justificación racional. A este respecto cabe señalar que en el supuesto básico de los casos (1) y (2) el Ministerio Público se ha conformado con la decisión del tribunal. Asimismo, en ambos casos la Corte ha anulado el fallo, resolviendo, en uno dictar sentencia de reemplazo (con el límite del art. 360 inciso $3^{\circ}$ ) y, en el otro, disponiendo la realización de un nuevo juicio. ¿Por qué no habría de regir el límite del art. 360 inciso $3^{\circ}$ del CPP en el caso (2)? Una respuesta negativa significaría que quien invoca un vicio in procedendo está en peor situación que alguien que invoca un error de derecho del cual se deriva la aplicación del art. 385 del CPP.

No debe olvidarse tampoco que la realización de un nuevo juicio está directamente vinculada a la interposición y acogimiento de un recurso de nulidad, por algunos de los motivos del art. 374 del CPP, así como la dictación de una sentencia de reemplazo está directamente conectada con la interposición y acogimiento de un recurso de nulidad por alguna causal del art. 373 del CPP que permita la aplicación del art. 385. ¿Por qué habría de hacerse distinción entre ambas situaciones?

Sostener que el nuevo tribunal tiene plena libertad para dictar sentencia, esto es, para calificar los hechos e imponer una pena más grave que la obtenida en el primer juicio que se anuló por exclusiva actividad recursiva de la defensa, afecta tres elementos esenciales en torno al ejercicio del derecho al recurso. En primer término, supone restar eficacia a los medios de impugnación y dejar entregado el ejercicio de un derecho fundamental a decisiones estratégicas que eviten que se haga realidad el dicho popular de "ir por lana y salir trasquilado". Supone, en segundo lugar, desconocer que tanto el Ministerio Público (que ha consentido o se ha conformado con la pena impuesta en el primer juicio) como el Tribunal de reenvío forman parte de la estructura del Estado - el uno destinado a enderezar la acción penal pública y el otro a juzgar a los presuntos responsables de un delito-, y que como órganos del Estado deben ser los verdaderos guardianes de esta garantía. Por último, y consecuente con lo recién apuntado, significa olvidar que la prohibición de la reformatio in peius es precisamente un límite punitivo oponible al Estado (y autoimpuesto), que en un sistema liberal y democrático debe asegurar la 
más completa y efectiva libertad en el empleo de los medios de impugnación, sin que la voluntad del acusado que estima injusta una sentencia resulte viciada por el temor de obtener al final del camino recursivo una sentencia más desfavorable.

La inteligencia de la verdadera relación entre la prohibición de la reformatio in peius y la realización de un nuevo juicio nos conduce a un principio interpretativo que permita proveer de mayor eficacia a la garantía comentada. Esta función la cumple, como se ha dicho antes, el principio pro homine o pro libertatis.

En la misma línea argumental es posible sostener que la interpretación de que la prohibición de reforma peyorativa existe sólo cuando se recurre de apelación o cuando la Corte anula y dicta sentencia de reemplazo, constituye una interpretación restrictiva de una garantía procesal penal, y en consecuencia una restricción del ejercicio de una facultad procesal (la de recurrir), que infringe por ello el art. 5 del CPP.

Además, significa desconocer el sistema de recursos del CPP, pues la apelación es procedente sólo en los procedimientos abreviados. En cambio, el recurso de nulidad constituye el único recurso procedente en los juicios orales (simplificados u ordinarios). En este estado de cosas, la prohibición de reforma en perjuicio sólo se aplicaría respecto de la apelación y de los recursos de nulidad por la causales del Art. 373 en relación con el art. 385, dejando fuera, según una interpretación restringida, los casos en que se anula la sentencia y el juicio, por la concurrencia especialmente de algún motivo del art. 374. Además de ser una interpretación restringida, resulta abiertamente injusta, en cuanto implica un tratamiento desigual para situaciones similares, cuyos supuestos son: no interposición de recursos por el Ministerio Público o el querellante particular, acogimiento del recurso interpuesto por el acusado y nulidad de la primera decisión jurisdiccional.

a.ii) Segunda alternativa: El segundo camino a seguir, supone que exista acuerdo en que la referencia a "la Corte" efectuada por el inciso $3^{\circ}$ del art. 360 del CPP significa que sólo procede la prohibición de la reformatio in peius en los casos en que la Corte dicta sentencia de reemplazo. Si ésta es la interpretación que se hace del texto legal, lo cuestionable entonces es la decisión del legislador de excluir la aplicación de la garantía que se analiza en los casos de recursos fundados especialmente en el art. 374 del CPP, pues, además de ser de utilidad restringida, carece de suficiente justificación racional, por lo que una norma con ese contenido no cumple el estándar constitucional del debido proceso.

Complementariamente, también estaríamos en presencia de una flagrante vulneración del art. 19 de la CPE en su numeral 26 que señala que se garantiza a todas las personas: "La seguridad de que los preceptos legales que por mandato de la Constitución regulen o complementen las garantías que ésta establece o que las limiten en los casos en que ella lo autoriza, no podrán afectar los derechos en su 
Barrientos - Prohibición de reformatio in peius...

esencia, ni imponer condiciones, tributos o requisitos que impidan su libre ejercicio".

La aceptación legislativa de la "tesis del riesgo previsible libremente asumido" por el acusado, implicaría, de ser esa la interpretación definitiva del art. 360 inciso $3^{\circ}$ del CPP, que el legislador ha afectado, mediante el traslado al acusado del riesgo peyorativo en la actividad recursiva, el núcleo o contenido esencial del derecho al recurso -integrado, entre otros elementos, por la prohibición de la reformatio in peius-, y su libre ejercicio, pues el perseguido penalmente estará condicionado en su impulso recursivo por consideraciones ajenas a la finalidad de los medios de impugnación, que no es otra que modificar en su favor la situación procesal determinada por una sentencia, sin temor de verse perjudicado por su propia actividad.

\section{PALABRAS FINALES}

Finalmente, debo reconocer que se ha abordado la aplicación de la prohibición de reforma peyorativa al juicio de reenvío desde la perspectiva de la jerarquía constitucional del derecho al recurso, como integrante del debido proceso. Esta decisión puede ser cuestionada por prescindir de un análisis técnico-procesal más riguroso de determinados aspectos surgidos a lo largo de este ensayo, tales como la naturaleza del juicio de reenvío, la competencia del tribunal de reenvío, la existencia de cosa juzgada parcial, el objeto del recurso, la pretensión recursiva y su amplitud, etc. ${ }^{67}$ Sin embargo, y compartiendo la necesidad de ahondar en dichos aspectos - los que sólo se han insinuado -, insisto en que la verdadera dimensión del problema planteado es constitucional, y no meramente procesal.

La jurisprudencia extranjera más avanzada así lo viene reconociendo desde hace muchos años. Ello ha llevado a Fernando De La Rúa, en su obra Teoría General del Proceso, a destacar que la evolución de la jurisprudencia argentina, en el tema analizado, dejó atrás un planteamiento puramente procesal para proyectarse a una consideración constitucional, en la que la prohibición de la reforma en perjuicio forma parte de un sistema de garantías.

A nadie puede escapar que el Derecho Procesal Penal permite la realización de garantías constitucionales en el ámbito de la administración de justicia y que la configuración de esas garantías se nutre del desarrollo de una copiosa jurisprudencia de tribunales internacionales. En nuestro ámbito, la actuación de la Corte Interamericana, que en materia del derecho al recurso tiene importantes fallos, no puede ser desconocida. Por esto, lleva razón Enrique

\footnotetext{
${ }^{67}$ Procuraré, en la medida de mis posibilidades, continuar el tratamiento de estas cuestiones a fin de satisfacer las observaciones que respecto de alguna de ellas ha formulado gentilmente el profesor Carlos del Río, de la Universidad Católica del Norte, Sede Coquimbo, a pedido del Dr. Manuel Núñez.
} 
REJ - Revista de Estudios de la Justicia - No 9 - Año 2007

Bacigalupo cuando dice, refiriéndose al contexto histórico de internacionalización de los derechos humanos, su constitucionalización y al surgimiento de jurisdicciones constitucionales y transnacionales, que: "En éste marco se puso rápidamente de manifiesto que el proceso penal tiene una estrecha relación con la Constitución del Estado". ${ }^{68}$ No se puede olvidar tampoco la célebre exclamación de Claus Roxin: “EEl Derecho Procesal Penal es el sismógrafo de la Constitución del Estado!”. ${ }^{9}$

Sin duda, quedan por resolver dos cuestiones procesales para que el tema analizado no sea una mera elucubración teórica: ¿Cómo plantear la aplicación de la interdicción de la reforma peyorativa en el segundo juicio? y ¿cómo impugnar una resolución que infringe dicha prohibición ${ }^{70} \mathrm{La}$ primera interrogante se resuelve mediante las alegaciones que se pueden hacer en relación a los factores relevantes para la determinación de la pena en el marco de la audiencia del art. 343 del CPP. La respuesta a la segunda cuestión debe considerar que, de acuerdo al inciso $2^{\circ}$ del art. 387 del CPP, no es susceptible de recurso alguno la sentencia que se dictare en el nuevo juicio que se realizare como consecuencia de la resolución que hubiere acogido el recurso de nulidad. Esto es, la sentencia del segundo juicio que eventualmente imponga una pena mayor que la que se impuso en el primero no es impugnable. Probablemente el recurso de queja será declarado inadmisible. En tal caso, la única alternativa es la promoción de una acción de amparo constitucional de acuerdo al art. 20 de la Constitución Política del Estado. El destino de esta acción dependerá del carácter (finalista o no) de la interpretación que se haga de la institución procesal que analizamos. No obstante es la única vía procesal, ante la carencia de un recurso extraordinario o de amparo, como el caso argentino y español, respectivamente, para plantear la vulneración de la prohibición de la reformatio in peius. ${ }^{71}$

\footnotetext{
68 Bacigalupo, Enrique, Derecho Penal y el Estado de Derecho, Editorial Jurídica de Chile, $1^{\circ}$ edición, Santiago de Chile, 2005, p. 168.

${ }^{69}$ Roxin, Claus, Derecho Procesal Penal, ob. citada, p. 10.

${ }^{70}$ Estas preguntas surgieron después de una interesante conversación con Hernán Díaz, Defensor Local de Calama, y con Roberto Vega, Defensor Local de Tocopilla, a quienes también agradezco sus comentarios.

${ }^{71}$ Por cierto queda como un tema abierto la constitucionalidad del art. 387 del CPP, especialmente en este supuesto, es decir, cuando hay imposición de pena más severa en el segundo juicio.
} 